\title{
Stimulus-response compatibility and psychological refractory period effects: Implications for response selection
}

\author{
MEI-CHING LIEN and ROBERT W. PROCTOR \\ Purdue University, West Lafayette, Indiana
}

\begin{abstract}
The purpose of this paper was to provide insight into the nature of response selection by reviewing the literature on stimulus-response compatibility (SRC) effects and the psychological refractory period (PRP) effect individually and jointly. The empirical findings and theoretical explanations of SRC effects that have been studied within a single-task context suggest that there are two response-selection routes-automatic activation and intentional translation. In contrast, all major PRP models reviewed in this paper have treated response selection as a single processing stage. In particular, the responseselection bottleneck (RSB) model assumes that the processing of Task 1 and Task 2 comprises two separate streams and that the PRP effect is due to a bottleneck located at response selection. Yet, considerable evidence from studies of SRC in the PRP paradigm shows that the processing of the two tasks is more interactive than is suggested by the RSB model and by most other models of the PRP effect. The major implication drawn from the studies of SRC effects in the PRP context is that response activation is a distinct process from final response selection. Response activation is based on both long-term and short-term task-defined S-R associations and occurs automatically and in parallel for the two tasks. The final response selection is an intentional act required even for highly compatible and practiced tasks and is restricted to processing one task at a time. Investigations of SRC effects and responseselection variables in dual-task contexts should be conducted more systematically because they provide significant insight into the nature of response-selection mechanisms.
\end{abstract}

In studies of human information processing, the processing stages of stimulus identification and response initiation are typically distinguished from a central processing stage that is often called response selection. Issues regarding response selection have been investigated thoroughly in two areas of research, stimulus-response compatibility (SRC) and psychological refractory period (PRP) effects. Fitts and Seeger (1953) were the first to demonstrate SRC effects, showing that performance depends not only on the individual properties of the stimuli and responses but also on their relation. A large empirical base regarding SRC effects exists, along with relatively sophisticated theoretical accounts of how response selection in single-task performance is affected by compatibility relations. Telford (1931) was the first to demonstrate the PRP effect, in which, when two tasks must be performed on successive stimuli, the response to the second stimulus is delayed when the interval between stimulus onsets is short. As for SRC effects, substantial empirical and theoretical work on the PRP effect has been conducted on how

We thank Bernhard Hommel, Hal Pashler, and an anonymous reviewer for their helpful comments on a previous version of this manuscript. Correspondence concerning this article should be addressed to M.-C. Lien, Mail Stop 262-4, NASA Ames Research Center, Moffett Field, CA 94035 or to R. W. Proctor, Department of Psychological Sciences, Purdue University, West Lafayette, IN 47907 (e-mail: mclien@ mail.arc.nasa.gov or proctor@psych.purdue.edu). response selection for one task is affected by response selection for another.

Although considerable research has been conducted on the SRC and PRP effects individually, few experiments have examined the two effects jointly. A reason for the lack of studies manipulating SRC in the PRP paradigm may lie in the belief that response selection for each task occurs the same way as it does in a single-task context. However, as Duncan (1979) pointed out, "In any PRP situation, the response sets of two single tasks have been combined to give a larger total set. It is perhaps unreasonable to suppose that this leaves unaffected the complexity of response choice" (p. 225). Moreover, Hommel (1998) demonstrated that considerable interaction occurs between the two tasks. The implication is that one cannot assume that response selection for each task in dual-task contexts is performed in the same manner as when each task is performed alone. Systematic examination of SRC effects in the PRP paradigm is necessary to provide a more complete understanding of the response-selection mechanism.

The purpose of the present paper, therefore, was to review SRC and PRP in the literature as they relate to issues of response selection and, most importantly, to examine in detail those studies that have looked at SRC effects in the PRP paradigm for any additional insights into the nature of response selection that they afford. We begin by reviewing SRC effects and the models developed to account for them. Such effects have been obtained for relevant and ir- 
relevant stimulus dimensions in a variety of tasks for which there is similarity among stimulus and response dimensions, and most current models include both automatic and intentional response-selection routes to account for these effects. We, therefore, discuss the functional aspects of the PRP models, along with pertinent empirical evidence. Most PRP models treat response selection as a single intentional process that operates separately for each task, in contrast to the models of SRC effects. The evidence suggests that there is a bottleneck in response selection, structural or strategic, that allows only one response to be selected at a time. Finally, we examine the influence of SRC in the PRP paradigm, showing that the PRP effect is resistant to elimination even with highly compatible tasks and that cross-talk occurs when there are similarities between the stimuli and responses for the two tasks. We conclude that the conception of response selection that best fits most results is one that distinguishes response activation, based on long-term and short-term associations, from final response selection.

\section{STIMULUS-RESPONSE COMPATIBILITY IN SINGLE-TASK PERFORMANCE}

\section{Effects of Relevant Stimulus Information}

SRC effects are differences in reaction time (RT) and accuracy, as a function of the mapping between stimulus and response sets or the members within the sets. Fitts and Seeger (1953) combined three stimulus panels $\left(\mathrm{S}_{\mathrm{a}}, \mathrm{S}_{\mathrm{b}}, \mathrm{S}_{\mathrm{c}}\right)$ with three response panels $\left(R_{a}, R_{b}, R_{c}\right)$ to generate nine stimulus-response ( $\mathrm{S}-\mathrm{R}$ ) ensembles (see Figure 1). The subject was to move one or two styluses to the response location(s) corresponding to the stimulus location(s). RT was shorter and error rate lower when the response panel corresponded physically with the stimulus display than when it did not-that is, for the combinations of $S_{a}-R_{a}$, $S_{b}-R_{b}$, and $S_{c}-R_{c}$. Fitts and Seeger attributed their results to the time it took for $\mathrm{S}-\mathrm{R}$ translation, stating, "A task involves compatible $S-R$ relations to the extent that the ensemble of stimulus and response combinations comprising the task results in a high rate of information transfer" (p. 199). Set-level compatibility effects of the type demonstrated by Fitts and Seeger, in which some combinations of $\mathrm{S}-\mathrm{R}$ sets yielded faster responses than others, are well documented (Kornblum, Hasbroucq, \& Osman, 1990).

Another type of SRC effect, called element-level compatibility, occurs when the $\mathrm{S}-\mathrm{R}$ sets are held constant but the mapping of individual stimuli to responses is varied. Fitts and Deininger (1954) used circular $S-R$ sets $\left(S_{a}\right.$ and $\mathrm{R}_{\mathrm{a}}$ in Fitts \& Seeger's, 1953, experiment; see Figure 1), with the mapping being direct, mirrored, or random. Direct mapping involved moving the stylus to the location corresponding to that of the stimulus. Mirrored mapping consisted of reversing the left-right relations while retaining

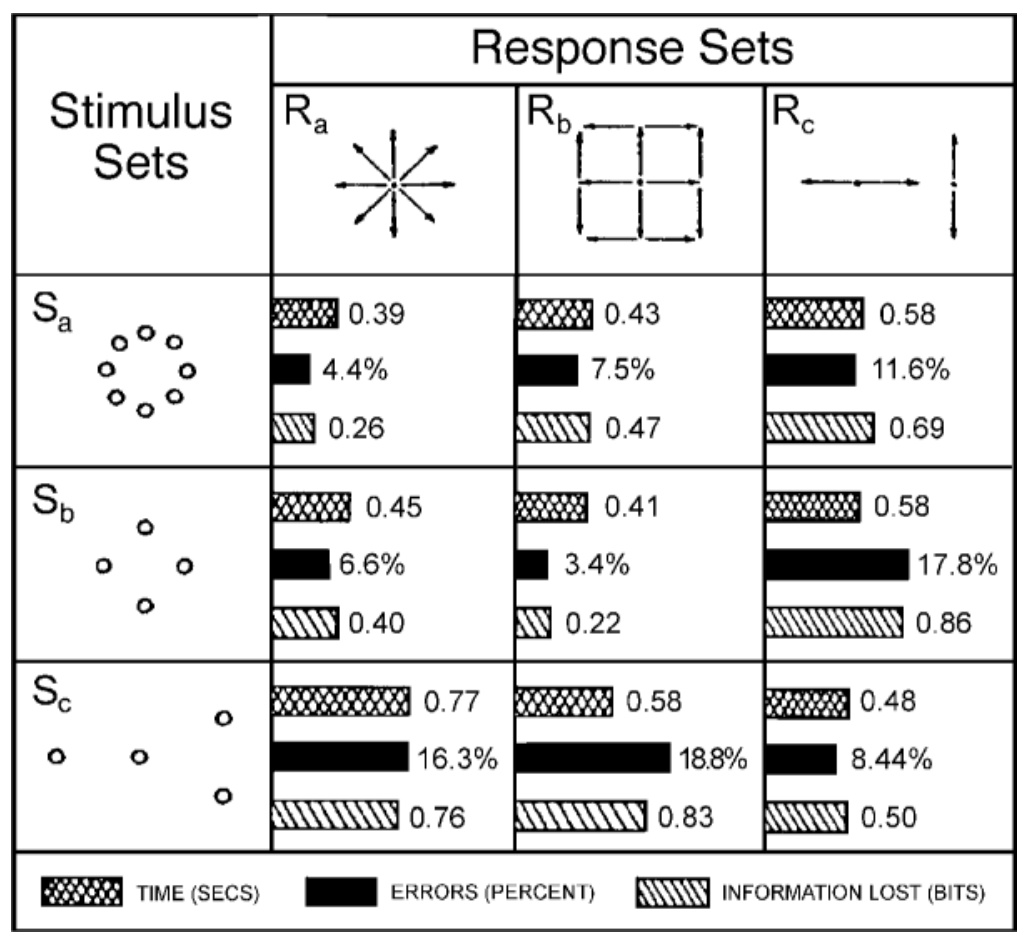

Figure 1. The three stimulus panels $\left(S_{a}, S_{b}\right.$, and $\left.S_{c}\right)$ and three response panels $\left(R_{a}\right.$, $R_{b}$, and $R_{c}$ ) used in Fitts and Seeger's (1953) Experiment 1, along with the response times and errors for each combination of stimulus and response panels. From " $\mathrm{S}-\mathrm{R}$ Compatibility: Spatial Characteristics of Stimulus and Response Codes," by P. M. Fitts \& C. M. Seeger, Journal of Experimental Psychology, 46, pp. 199-210, Figure 1. Copyright 1953 by the American Psychological Association. Adapted with permission. 
the relations in the vertical dimension. For random mapping, stimuli were arbitrarily assigned to responses. Responses were fastest for direct mapping (387 msec), intermediate for mirrored mapping (541 msec), and slowest for random mapping $(1,111 \mathrm{msec})$. Several authors have attributed the advantage for mirrored mapping over random mapping to the fact that a single $\mathrm{S}-\mathrm{R}$ translation rule (respond at the mirror opposite location) can be applied to all stimulus elements for mirrored mapping but not for random mapping (e.g., Duncan, 1977a; Rosenbloom \& Newell, 1987).

Pure and mixed spatial mappings. Most SRC research since that of Fitts and colleagues (Fitts \& Deininger, 1954; Fitts \& Seeger, 1953) has been conducted with two- or fourchoice tasks in which subjects make keypress responses to the alternative stimuli with different spatial mappings. When left and right visual stimulus locations are assigned to left and right keypresses made with the index fingers of the respective hands, RT is shorter when the mapping is spatially compatible (i.e., left response to left stimulus and right response to right stimulus) than when it is not (i.e., right response to left stimulus and left response to right stimulus). When the hands are crossed, so that the left hand operates the right key and the right hand the left key, RT is slowed, but the advantage for the compatible mapping is approximately the same magnitude as when the hands are uncrossed (e.g., Roswarski \& Proctor, 2000). This finding indicates that the mapping effect is primarily a function of the spatial relations between stimuli and responses, not between stimuli and responding hands. In most cases, the important spatial relation is the relative position of the two stimuli and the two responses (e.g., Umiltà \& Nicoletti, 1990). These results have been interpreted as implying that response selection in two-choice tasks is based on spatial stimulus and response codes (Hommel, 1997).

In most SRC studies, only a single mapping, compatible or incompatible, is in effect at any time. There are some studies, however, that have examined mixed mapping conditions, in which some stimuli are mapped to responses incompatibly and others compatibly. These studies are relevant to the PRP literature because PRP studies typically involve two different S-R mappings. Duncan (1977b) used either a single mapping rule (pure condition) or multiple rules (mixed condition) in a four-choice reaction task. Figure 2 shows various mappings between four stimuli and four keypress responses. In the pure conditions, the appropriate rule (same or opposite) could be applied to the stimulus to produce the required response. Duncan (1977b) proposed that in the mixed conditions, response selection proceeds in two steps: The appropriate rule for the stimulus is selected, then this rule is applied. Consistent with this two-step process, RT was longer under mixed conditions than under pure conditions, and an error was most likely to be the response that would be correct if the inappropriate mapping rule were applied to the stimulus. These results have been replicated in several studies (Duncan, 1977a, 1979; Ehrenstein \& Proctor, 1998; Stoffels, 1996),

\section{CONDITION P-C}

$\begin{array}{ccccc}\text { Stimuli } & 1 & 2 & 3 & 4 \\ & \downarrow & \downarrow & \downarrow & \downarrow \\ \text { Responses } & \mathrm{A} & \mathrm{B} & \mathrm{C} & \mathrm{D}\end{array}$

Mean RTs Outer Stimuli $(1$ and 4$)=445 \mathrm{msec}$ Inner Stimuli $(2$ and 3$)=410 \mathrm{msec}$

\section{CONDITION M-1}

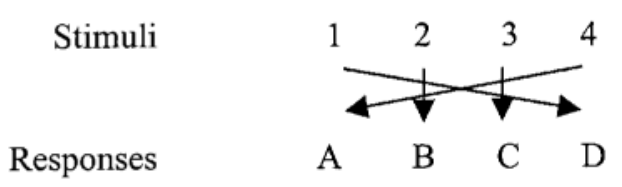

Mean RTs Outer Stimuli $(1$ and 4$)=540 \mathrm{msec}$ Inner Stimuli $(2$ and 3$)=490 \mathrm{msec}$

\section{CONDITION P-O}

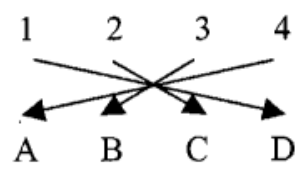

Outer Stimuli $(1$ and 4$)=510 \mathrm{msec}$ Inner Stimuli $(2$ and 3$)=465 \mathrm{msec}$

\section{CONDITION M-2}

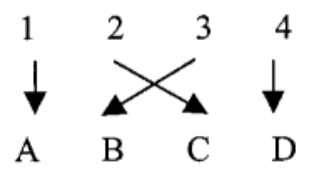

Outer Stimuli $(1$ and 4$)=575 \mathrm{msec}$ Inner Stimuli $(2$ and 3$)=645 \mathrm{msec}$

Figure 2. The four stimulus-response (S-R) mapping rules used in Duncan's (1977b) study. The stimuli are numbered 1 to 4 from left to right (1 and 4 are outer and 2 and 3 are inner), and the responses are labeled $A$ to $D$ from left to right. The arrows show the mapping of each stimulus to its assigned response. Condition P-C is pure corresponding mapping. Condition P-O is pure opposite mapping. Condition M-1 is mixed mapping, Version 1 , for which the $S-R$ pairs of inner stimuli are corresponding and outer stimuli are opposite. Condition M-2 is mixed mapping, Version 2, for which the $S-R$ pairs of inner stimuli are opposite and outer stimuli are corresponding. Mean reaction times (RTs) are estimated from Duncan's Figure 2. 
with the major deviation from Duncan's (1977b) original findings being that mixing typically slows RT more for compatible mapping than for incompatible mapping.

The effect of mixing is particularly strong when two stimuli are mapped to two responses and the mapping for a given trial is conveyed by a signal presented simultaneously with the imperative stimulus. Shaffer (1965) found that the SRC effect obtained in pure blocks was eliminated entirely in this situation. The most widely accepted explanation for the reduction or elimination of the SRC effect with mixed mappings is in terms of alternative responseselection routes (Ehrenstein \& Proctor, 1998; Stoffels, 1996). According to this explanation, when all S-R mappings are compatible, response selection occurs via a direct, or automatic, route that produces activation through long-term $\mathrm{S}-\mathrm{R}$ associations. When mappings are mixed or incompatible, the direct route is suppressed, and response selection occurs via an intentional translation route. Consequently, with mixed mappings, there is an extra cost for compatible mapping, relative to incompatible mapping, associated with suppression of the direct route.

Influence of $\mathbf{S}-\mathbf{R}$ modes. Mapping effects occur in two- and four-choice tasks not only for visual stimuli but also for auditory stimuli (e.g., Simon, 1969) and not only with keypresses but also with unimanual aimed, switch, and joystick movements (e.g., Proctor \& Wang, 1997). Mapping effects also occur when the stimuli are the words left and right or are arrows pointing to the left and right, as well as when the responses are the spoken words "left" and "right" (e.g., Wang \& Proctor, 1996). However, the mode relation between $\mathrm{S}-\mathrm{R}$ sets influences the magnitude of the SRC effects. Wang and Proctor found that when left and right visual stimuli were mapped compatibly to left and right responses, interactions were obtained indicating that the verbal/vocal and spatial/manual (or arrow/manual) S-R combinations had higher set-level compatibility than did the verbal/manual and spatial/vocal (or arrow/vocal) combinations.

More generally, when verbal stimuli of any type are paired with vocal naming responses, performance is better when the task requires naming the stimulus (e.g., saying " $\mathrm{A}$ " to the letter $A$ ) than when it requires saying another name (e.g., saying "B" to the letter $A$ ). Greenwald (1970a) compared compatible mappings of letters presented visually or auditorily with spoken or written letteridentification responses. RTs were shorter for the combinations of spoken responses to auditory stimuli and written responses to visual stimuli than for the other combinations. Greenwald (1970a) interpreted these results as being in support of the concept of ideomotor compatibility; S-R sets are ideomotor compatible if the feedback from the required response resembles the stimulus. For this experiment, the assumption Greenwald (1970a) made is that the most important feedback modality for spoken responses is audition and that for written responses is vision. Ideomotor compatibility has been assigned a crucial role in the ability to perform dual tasks simultaneously with little or no interference, as is discussed later in this paper.

Influence of practice. Several studies have suggested that SRC effects decrease with practice, implying that the major effect of practice is on response selection (Fletcher \& Rabbitt, 1978; Mowbray \& Rhoades, 1959; Proctor \& Dutta, 1993). Teichner and Krebs (1974) studied RT as a function of the number of $\mathrm{S}-\mathrm{R}$ alternatives and the amount of practice for digit-key and light-key arrangements. They reported that even with an arbitrary S-R mapping, as in the digit-key task, RT can become relatively short after extensive practice. Pashler and Baylis (1991) evaluated practice effects for conditions in which symbols were assigned to each of three keypresses by categories or arbitrarily. RT was faster with categorical mapping than with arbitrary mapping. Both mappings showed large decreases in RT with practice, but the benefit of practice was larger for arbitrary mapping. On the basis of transfer effects, Pashler and Baylis concluded that the primary influence of practice for both mappings is on response selection.

Although SRC effects are reduced with practice, there is no study of which we are aware in which they have been eliminated entirely. In their Experiment 2, Fitts and Seeger (1953) had subjects practice in 26 sessions, each of which contained 16 trials with three combinations of $\mathrm{S}-\mathrm{R}$ sets $\left(S_{a}-R_{a}, S_{b}-R_{a}\right.$, and $S_{c}-R_{a}$ in Figure 1). The advantage for the most compatible set $\left(S_{a}-R_{a}\right)$ over the least compatible set $\left(\mathrm{S}_{\mathrm{c}}-\mathrm{R}_{\mathrm{a}}\right)$ was $450 \mathrm{msec}$ in Session 1. This was reduced to $75 \mathrm{msec}$ in Sessions 17-26, but in no session was RT faster for the incompatible set than for the compatible set. Dutta and Proctor (1992) used a procedure in which each subject practiced with only a single compatibility condition for eight sessions of 300 trials each. In their Experiment 1 , subjects performed a standard two-choice left-right spatial task, in Experiment 2, an orthogonal two-choice task (up-down stimuli mapped to left-right responses, for which the up-right/down-left mapping is compatible), and in Experiment 3, a two-dimensional, symbolic fourchoice task (the letters $O, o, z, Z$ mapped to four response keys, for which a left-to-right mapping of $\mathrm{OozZ}$ is more compatible than a mapping of $O z o Z$ ). In all cases, the SRC effect decreased across the first few sessions but was still evident in the remaining sessions. Similarly, in Pashler and Baylis's (1991) study in which each subject practiced with either the categorical or arbitrary mapping, the RT advantage for the categorical mapping, though smaller than in the initial session, was still $75 \mathrm{msec}$ in the last, 15th practice block. Thus, although the improvement in response selection with practice is greater for incompatible than compatible $\mathrm{S}-\mathrm{R}$ mappings, SRC effects are still evident after considerable practice.

\section{Effects of Irrelevant Stimulus Information}

Not only is an SRC effect found when spatial stimulus information is relevant to the task but also when it is irrelevant (known as the Simon effect). Simon and his colleagues conducted experiments using two-choice tasks in 
which left or right responses were made to high- or lowpitch tones that occurred in the left or right ear. Even though tone location was irrelevant to the task, RT was shorter when tone location corresponded to response location than when it did not (see Simon, 1990, for a review). Effects of irrelevant location are also obtained with visual stimuli. Craft and Simon (1970) had subjects respond to a red or green light displayed in a left or right location. RT was faster when the location of the stimulus corresponded to the location of the assigned response than when it did not.

Simon and Acosta (1982) had subjects make a left or right keypress to a visual $X$ or $O$, with an irrelevant tone presented simultaneously in the left or right ear. RT was shorter when tone location corresponded to response location than when it did not. This outcome, called the accessory stimulus version of the Simon effect, illustrates that the effect can be found when the relevant and irrelevant stimulus information is presented in different objects in different modalities. Moreover, the effect occurs when tone onset precedes onset of the imperative stimulus by up to at least $550 \mathrm{msec}$ (Proctor \& Pick, 1998), a range of intervals similar to that used for presentation of the two stimuli in the PRP paradigm.

Simon, Hinrichs, and Craft (1970) had subjects respond to a high-or low-pitch tone, presented in the left or right ear, with their hands uncrossed in one block and crossed in another. RT was shorter when the tone location was the same as the response location, regardless of whether the hands were crossed or uncrossed. Wallace (1971) obtained similar results for the crossed and uncrossed hand placements with visual stimuli for the Simon effect. Thus, as when stimulus location is relevant, the correspondence between stimulus and response locations, rather than between stimulus location and response hand, is the primary factor that causes the Simon effect. Because stimulus location is irrelevant, most accounts of the Simon effect consider that it is a consequence of automatic activation of the corresponding response code.

Task instructions and response goals. All of the studies of the Simon effect described so far have used a mapping condition in which the relevant stimulus information was unrelated to the response. In this case, there is an advantage when the stimulus location corresponds to the response location compared with when it does not. However, this effect does not reflect an obligatory tendency to activate the corresponding response automatically. Hedge and Marsh (1975) conducted a study in which a red or green circle was presented in a left or right location, with the location being irrelevant to the task. A movement of a finger from a home key to one of two response buttons, labeled with a red or green color, was made in response to the stimulus color. Half of the subjects used compatible $S-R$ color mapping and half incompatible mapping. With compatible S-R color mapping, a normal Simon effect was found. However, with the incompatible $S-R$ color mapping, a reverse Simon effect was evident. RT was shorter when the response location did not correspond to the stimulus location than when it did.
Hedge and Marsh (1975) interpreted the reverse Simon effect obtained with the incompatible color mapping in terms of a logical recoding hypothesis. According to this hypothesis, when mapping is incompatible, the stimulus color is recoded into the alternative color by applying a respond opposite rule. This rule is also applied inadvertently to the irrelevant stimulus location, leading to shorter RT when the stimulus location does not correspond with the response location than when it does. The Hedge and Marsh reversal has been replicated in several studies (e.g., Lu \& Proctor, 1994). Although alternative interpretations have been provided in terms of display-control arrangement correspondence (Simon, Sly, \& Vilapakkam, 1981) and competition in stimulus identification (Hasbroucq \& Guiard, 1991), logical recoding remains the most widely accepted account (see Lu \& Proctor, 1995, for a review).

Whereas Hedge and Marsh (1975) found effects of whether the relevant $\mathrm{S}-\mathrm{R}$ color mapping was same or opposite, Hommel (1993a) found effects of whether the location of the response goal was the same as or opposite to that of the response effector. He conducted a standard Simon task with tone pitch being relevant, tone location being irrelevant, and the hands placed normally on the keys (i.e., the left hand pressed the left key, and the right hand pressed the right key). In some conditions, a right keypress turned on a left light and a left keypress a right light. In the control condition, subjects were instructed to ignore the lights and press the left key in response to the low-pitch tone and the right key in response to the highpitch tone. In the experimental condition, they were instructed to trigger the light on the right side in response to the low-pitch tone and the light on the left side in response to the high-pitch tone. A Simon effect was obtained in the control condition, with RT being faster when the tone location was the same as the response location. However, the experimental group showed faster RT when the locations of the tone and light were the same than when they were different. Hommel concluded that the critical factor in the SRC effect is the correspondence between stimulus location and response-goal location. Riggio, Gawryszewski, and Umiltà (1986) obtained similar results for SRC proper. They had subjects respond to stimulus location and found the SRC effect to be a function of the location of the response keys when they were operated by sticks held by the contralateral hand (e.g., left key operated by a stick held at the right side in the right hand). The major implication of these studies is that the response activation produced by irrelevant and relevant stimulus information is dependent on task instructions and response goals.

Influence of S-R modes. As with SRC proper, the Simon effect occurs when the irrelevant location information is conveyed by arrow direction or location word (Proctor \& Vu, in press). When the responses are leftright keypresses, the effect is largest when the irrelevant information is left-right location and smallest when it is the word left or right. In contrast, when the responses are the vocal names "left" and "right," the location words produce the largest Simon effect. These results imply that an 
irrelevant stimulus dimension that is conceptually similar to the response dimension produces response activation through the long-term associations of the concepts. The strength of activation varies as a function of the perceptual similarity of the stimuli and responses, being greatest for spatial stimuli paired with keypress responses and location words paired with vocal location-name responses.

The closely related Stroop (1935/1992) effect shows that the correspondence effect patterns are dependent on which stimulus information is defined as relevant and its relation to the response modality for the task. In Stroop's original task, subjects were required to name the ink color in which a word was printed. When the word was the name of an incompatible color (e.g., RED printed in green ink), people were substantially slower to name the ink color than in a neutral condition (e.g., XXX printed in green ink). However, when the task was to read the color words, there was little effect of an irrelevant ink color. The dependence of the Stroop effect on task requirements is illustrated more clearly in a version of the Stroop task in which location words are paired with stimulus locations. A standard finding is that keypress responses to location words are faster when the word appears at a correspondinglocation than at a noncorresponding location (e.g., a left keypress to the word LEFT when it appears on the left side), but keypresses to stimulus location are relatively unaffected by location word (O’Leary \& Barber, 1993; Virzi \& Egeth, 1985). In contrast, when the responses are spoken location words, the interference pattern reverses and spatial words produce a large effect on responding to locations, but locations do not have much effect on responding to location words. Thus, response modality is a major factor in determining the magnitude of the correspondence effect produced by the irrelevant information.

A similar result is obtained when the spatial dimensions are arrow direction and location word. Baldo, Shimamura, and Prinzmetal (1998) conducted an experiment in which stimuli were a left or right pointing arrow paired with the word left or right, and keypresses or vocal responses were made to either the arrow or the word. Large Stroop effects were obtained with keypresses when the word was relevant and the arrow irrelevant and with vocal responses when the arrow was relevant and the word irrelevant. Only small effects were observed when keypresses were made to arrows and vocal responses were made to words.

Following an approach similar to Greenwald's (1970a) ideomotor theory, but with an emphasis on $\mathrm{S}-\mathrm{R}$ coding, Virzi and Egeth (1985) proposed a model that incorporates the relation between stimulus and response codes, suggesting that there is a linguistic system for processing verbal stimuli and vocal responses and a spatial system for processing spatial stimuli and manual responses. Accordingly, any task in which the stimulus information is linguistic (words, letters, or digits) benefits from the use of vocal rather than manual responses. In contrast, any task in which the stimulus information is of a spatial-analogue nature, such as in arrow direction tasks, benefits from the use of manual responses. However, because Virzi and Egeth's model treats the relation of stimulus and response modalities as all or none, it has difficulty explaining the small correspondence effects obtained when the irrelevant stimulus dimension and the responses are in different “systems" (Baldo et al., 1998; Lu \& Proctor, 2001; O’Leary \& Barber, 1993). Rather than irrelevant information's producing no activation when the response is in a different system, a small amount of activation is produced that appears to reflect the weaker associations between the modalities of the irrelevant stimulus dimension and the response.

Task-defined S-R associations. For the studies of the Simon effect described above, the irrelevant stimulus dimension is conceptually similar to the response dimension in all cases but is not mapped by the instructions to the responses. Consequently, the activation of the corresponding response that occurs when a stimulus is presented must be by way of long-term $\mathrm{S}-\mathrm{R}$ associations. A closely related correspondence effect, called the Eriksen flanker effect, shows that effects of irrelevant stimulus information occur when the stimulus dimension is not conceptually similar to the response dimension but has been associated with the responses by the task instructions (B. A. Eriksen \& C. W. Eriksen, 1974; Miller, 1987, 1991). C. W. Eriksen and Hoffman (1972) had subjects make keypresses to a target letter, such as pressing the left key for $A$ or $U$ and the right key for $H$ or $M$, that occurred in the 9 o'clock position of a circular display. The remaining positions in the display were other letters (called flankers), which subjects were instructed to ignore. When the flankers belonged to the opposite letter category as the target (e.g., the letter $M$ surrounding a target letter $A$ ), response to the target letter was slower. However, the response was faster when the flankers were within the same letter category as the target (e.g., the letter $U$ surrounding a target letter $A$ ). The Eriksen effect shows that flankers produce activation of the responses to which they are associated by the task instructions, even though there is no conceptual similarity of the letters to the keypress responses. More importantly, the Eriksen effect suggests that automatic response tendencies are not restricted to spatial information but can be activated more generally by the specific task requirements.

The role of task-defined $\mathrm{S}-\mathrm{R}$ associations in the effects of irrelevant information is sufficiently strong to reverse the Simon effect when these associations are spatially incompatible. When location-irrelevant trials are mixed with location-relevant trials for which $\mathrm{S}-\mathrm{R}$ mapping is incompatible, the Simon effect reverses to a large advantage for the noncorresponding location (Marble \& Proctor, 2000). The results show little evidence of a contribution of the long-term $\mathrm{S}-\mathrm{R}$ associations to the Simon effect and a substantial contribution of the short-term, task-defined $\mathrm{S}-\mathrm{R}$ associations. Similarly, a small amount of practice with incompatible mapping of stimulus locations to response locations eliminates the Simon effect when location is subsequently made irrelevant (Tagliabue, Zorzi, Umiltà, \& Bassignani, 2000), and a larger amount of prac- 
tice reverses the Simon effect (Proctor \& Lu, 1999). The influence on the Simon effect of practice with incompatible spatial mapping seems to be mediated by a continued contribution of the short-term $\mathrm{S}-\mathrm{R}$ associations that were previously relevant (Tagliabue et al., 2000).

On the whole, the effects obtained from the various tasks described above suggest that they have a similar processing basis in response selection. All of them show that the $\mathrm{S}-\mathrm{R}$ relationship impacts human performance even if it is completely irrelevant to the task. In general, SRC effects can be found for various task types and modalities, for the processing of the same or different stimuli, and for the spatial and semantic dimensions. The automatic activation produced by the irrelevant stimulus information might interfere with the identification of the relevant stimulus information, but the major effect seems to occur at the stage of response selection and to depend on the overall task requirements.

\section{Theoretical Accounts of Stimulus-Response Compatibility Effects}

The studies reviewed in the previous section suggest that two response-selection routes-intentional translation and automatic activation-play roles in SRC effects. Several theories have incorporated these factors to explicate various findings (e.g., De Jong, Liang, \& Lauber, 1994; Hommel, 1993b, 1997). Two major dual-route theoretical accounts - the dimensional overlap model and the actionconcept translation model - have been proposed to explain SRC effects in single-task conditions.

Dimensional overlap model. Kornblum and his colleagues (Kornblum, 1992, 1994; Kornblum et al., 1990; Kornblum \& Lee, 1995) proposed a dimensional overlap model (DOM) and a task taxonomy of SRC that incorporates the distinction between set- and element-level determinants of compatibility. According to the DOM, when the relevant stimulus and response dimensions are conceptually, perceptually, or structurally similar, the stimulus will trigger two response functions: automatic activation of the congruentresponse and intentional identification of the assigned response. If an irrelevant stimulus overlaps with the response dimension, it will also produce automatic activation of the corresponding response but will not be identified through intentional translation. If a response that is automatically activated by either a relevant or irrelevant stimulus dimension is the one assigned to the relevant stimulus dimension by the task instructions, it can be executed as soon as identification is completed, and RT will be facilitated. In contrast, if the automatically activated response is not the correct one, it must be inhibited before the correct response can be programmed and executed, thus slowing RT.

Dimensional overlap will also influence the speed of the intentional response-identification process. Response identification will be fastest with congruent $S-R$ mapping because an identity rule (i.e., respond at the corresponding location) can be applied. For incongruent mapping, re- sponse identification will be slowest if the stimuli are randomly assigned to responses, because identification of the response must proceed by a time-consuming search through specific task-defined $\mathrm{S}-\mathrm{R}$ associations. The time for response identification will be reduced when there is a systematic relation between stimuli and responses that allows application of a single mapping rule (e.g., respond at mirroropposite location).

Kornblum and Lee (1995) expanded the DOM to include conflict between overlapping relevant and irrelevant stimulus dimensions (e.g., as in the Eriksen flanker task). In the model, overlap between the two stimulus dimensions is presumed to produce conflict in the stimulus identification stage of processing when the dimensions are not in agreement. This overlap of the two dimensions will thus affect the time for stimulus identification, prior to the initiation of response selection. The inclusion of this additional kind of overlap led Kornblum and Lee to propose a taxonomy that classifies tasks into eight categories (see Table 1) on the basis of dimensional overlap between (1) the relevant stimulus information and the response, (2) the irrelevant stimulus information and the response, and (3) the relevant and irrelevant stimulus dimensions. The eight task types defined by the taxonomy extend from Type 1 ensembles, for which there is no overlap of the relevant and irrelevant stimulus dimensions with each other or with the response dimension, to Type 8 ensembles, for which there is overlap of all three types.

Kornblum and his colleagues have tested the DOM in a series of studies using the task taxonomy to classify tasks in terms of their dimensional overlap properties (Kornblum, 1992; Kornblum \& Lee, 1995; Kornblum, Stevens, Whipple, \& Requin, 1999; Zhang \& Kornblum, 1998). Many of their findings are generally consistent with the DOM. For example, Zhang and Kornblum used congruent and incongruent $S-R$ mappings in their Experiment 1 and asked subjects to respond to one of two types of words (color word or digit word) presented in the middle of the

Table 1

A Taxonomy of Stimulus-Response Ensembles From Kornblum's (1992) Dimensional Overlap Model

\begin{tabular}{cccc}
\hline & \multicolumn{3}{c}{ Overlapping Ensemble Dimensions } \\
\cline { 2 - 3 } Ensemble Type & Stimulus-Response Dimensions & $\begin{array}{c}\text { Stimulus-Stimulus } \\
\text { Dimensions }\end{array}$ \\
\cline { 2 - 4 } & Relevant & Irrelevant & No \\
\hline 1 & No & No & No \\
3 & Yes & No & No \\
4 & No & Yes & Yes \\
5 & No & No & No \\
6 & Yes & Yes & Yes \\
7 & Yes & No & Yes \\
8 & No & Yes & Yes \\
\hline
\end{tabular}

Note-From "Dimensional Overlap and Dimensional Relevance in Stimulus-Response and Stimulus-Stimulus Compatibility," by S. Kornblum, 1992, in G. E. Stelmach \& J. Requin (Eds.), Tutorials in Motor Behavior II (pp. 743-777). Amsterdam: North-Holland. Copyright 1992 by Elsevier Sciences, Ltd. Reprinted with permission. 
two irrelevant words. The irrelevant words were either from the same or different word type. Two response sets, color naming and digit naming, were combined with the two stimulus sets to form four different $\mathrm{S}-\mathrm{R}$ ensembles. Types 2 , 3 , and 4 ensembles each possessed only one of the three types of dimensional overlap, whereas Type 8 ensembles had dimensional overlap of all three types. Zhang and Kornblum developed an interactive activation network based on the DOM that was able to fit the data for all four ensembles, treating Types 2, 3, and 4 as interactive constituent components of the Type 8 ensembles.

The DOM is able to offer explanations for several compatibility effects, including element-level mapping effects, set-level modality effects, the Simon effect, and the Stroop and flanker effects. It makes the important point that SRC effects are not simply a function of spatial stimuli and responses but occur for many situations in which stimulus sets have similarity with the response sets. However, there are several problems associated with the assumptions of the model. First, the assumption that a stimulus automatically activates its corresponding response, regardless of the task-defined $\mathrm{S}-\mathrm{R}$ mapping, is challenged by the finding that the Simon effect is reversed when an incompatible location mapping has been practiced previously (Proctor \& Lu, 1999) or is currently in effect for mixed location-relevant trials (Marble \& Proctor, 2000). Second, the assumption that overlap between the relevant and irrelevant stimulus dimensions affects the time for stimulus identification but not response selection is questionable. Tasks such as the Eriksen flanker task, for which there is no overlap of the stimulus dimensions with the responses, show interference from a flanker through its being assigned to an alternative response and little influence when it is not assigned to any response (B. A. Eriksen \& C. W. Eriksen, 1974). This implies that in such tasks the correspondence effect is largely a function of response activation based on the task-defined S-R assignments, which is consistent with the physiologicalevidence of response preparation in the lateralized readiness potential and electromyography (Coles, Gratton, Bashore, Eriksen, \& Donchin, 1985).

Another assumption of the DOM is that the three types of similarity - perceptual, conceptual, and structuralhave the same effect on processing (Kornblum \& Lee, 1995). However, evidence suggests that they do not (Proctor \& Wang, 1997). Finally, although the model assumes that dimensional overlap varies along a continuum and is influenced by the three types of similarity, the task taxonomy (1) is based solely on conceptual similarity and (2) treats dimensional overlap as all or none rather than as continuous. As a consequence, though several correspondence effects can be derived using the taxonomy to specify dimensional overlap, as in Kornblum and Lee's study, some effects cannot be predicted by doing so. For example, the Stroop color-naming task and the spatial Stroop task, in which there is conceptual overlap between the relevant stimulus dimension, the irrelevant stimulus dimension, and the response dimension (Type 8 ensembles), yield Stroop effects of different magnitudes as a function of whether the color word is relevant or irrelevant. As described earlier, little Stroop effect is obtained when the color word, rather than the color itself, is named (MacLeod, 1991). Similarly, Lu and Proctor (2001) found that, with keypresses, the effect of irrelevant arrow direction on responding to a relevant location word was larger than that of an irrelevant location word on responding to relevant arrow direction. Such asymmetric effects are not predicted by the DOM when dimensional overlap is defined from the taxonomy, because the taxonomy does not differentiate the modality (verbal, nonverbal) in which the information is presented.

Action-concept translation model. Hommel (1997) proposed an action-concept model of $\mathrm{S}-\mathrm{R}$ translation to account for relevant and irrelevant SRC effects. The model assumes that stimuli and actions ${ }^{1}$ are not represented by single, unitary codes, but by codes of their features that can be processed and interact within the same system. When the task requires responding to one stimulus feature (i.e., color), that feature has to be temporarily linked to one of the response features (an action concept or effect code) associated with the motor pattern before the response can be executed. Upon stimulus presentation, a stimulus feature activates a response code through pre-existing associations, regardless of whether the feature is relevant or irrelevant to the task, and through the temporary links if it is relevant. Because stimulus and response features are within the same system, activation of a response feature will also produce activation of a stimulus feature to which it is linked, having an impact on stimulus identification.

The action-concept model also includes the concepts of automatic activation and decay of irrelevant stimulus codes in a dual-route $\mathrm{S}-\mathrm{R}$ translation framework. Hommel (1997) assumed that the processing of relevant and irrelevant stimulus information is independent and overlaps in time. When stimulus location is irrelevant, as in the Simon task, the corresponding response is activated quickly, and this activation then decays. As predicted by this activation/decay notion, manipulations that slow responding often reduce the magnitude of the Simon effect (Hommel, 1993b, 1994; Lu \& Proctor, 1994; Roswarski \& Proctor, 1996). Also, when the RT distributions are partitioned into quintiles or deciles, the Simon effect tends to decrease as the RT increases (De Jong et al., 1994).

Of particularinterest is a finding of Soetens (1998) that the Simon effect was smaller when the onset of the next stimulus in a trial sequence occurred shortly after the previous response (50-msec interval) than when the onset was delayed (1,000-msec interval). Because the responses were slower in the short-interval condition, the reduction of the Simon effect could be due to decay of the automatic activation of the corresponding response. An implication of this finding for the PRP paradigm, which requires responses to two stimuli in close succession, is that the Simon 
effect (as well as other effects of irrelevant information) on the second task might be reduced simply because the response is delayed.

The general point of the temporal properties of the actionconcept translation model is that the larger the temporal overlap between the response activation produced by irrelevant and relevant stimulus features, the larger the correspondence effect. Lu and Proctor (2001) showed that when a location word is irrelevant and the arrow direction is relevant, the correspondence effect increases as the interval between the onsets of the word and the arrow increases to 200-300 msec and then decreases as the interval increases further. This inverted U-shaped function is likely a consequence of the peak activation produced by the irrelevant word taking longer to occur than that produced by the irrelevant location in the Simon task.

On the basis of the assumption that stimulus and response processing takes place within the same system, the action-conceptmodel predicts that preselecting a response should not prevent it from being interfered with by the processing of stimulus codes. Thus, if the response has not been executed, compatibility effects should be evident when it is precued or held constant within a trial block. Moreover, Hommel (1996) assumed that processing the relevant stimulus information in a simple RT task is faster than processing the spatial information. This assumption implies that the spatial stimulus code is more likely to affect performance when the response is not made quickly. Hommel performed a bin analysis of the RT distributions for both precuing and blocking conditions by using the individual means for the 1 st to 5 th quintiles of the rank-ordered RTs from correspondence and noncorrespondence trials. As predicted, correspondence effects were absent at the shortest bin and increased steadily as the RT bin increased.

Activation and decay functions of the type proposed by Hommel (1997) were not initially part of Kornblum et al.'s (1990) DOM, described previously. However, because the DOM is a relative activation strength model, temporal activation properties can be incorporated within it. Such functions have in fact been included in a recent connectionist network implementation of the model by Kornblum et al. (1999).

\section{Summary}

When stimulus location is relevant, responses are faster and more accurate when the stimulus and response locations correspond than when they do not. Likewise, when symbolic identity is relevant and the stimulus location irrelevant, responses are faster when stimulus location corresponds to the response location. The correspondence effects for irrelevant stimulus location vary as a function of the locations of the action goals, rather than the locations at which the responses are made. Comparable SRC effects are obtained with a range of stimulus and response dimensions when at least one pair of dimensions is similar or has high overlap. However, overlap of an irrelevant stimulus dimension with a response is not necessary to obtain cor- respondence effects. For example, in the Eriksen flanker effect, a stimulus that flanks the target stimulus in positions defined as irrelevant produces a correspondence effect if it has been assigned to a response or if it is highly correlated with a particular target.

Most current explanations of SRC effects incorporate two response-selection routes-automatic activation and intentional S-R translation. When a stimulus occurs, it may automatically activate its corresponding response by way of long-term associations, even if that response is not correct. This automatic activation appears to decay when the stimulus dimension that produces it is irrelevant to the task, with the consequence that the correspondence effect decreases as responding is delayed. Intentional translation is presumed to occur on the basis of short-term S-R associations defined by the task. When $\mathrm{S}-\mathrm{R}$ mapping is systematic, translation can occur by application of a rule, rather than via the specific $\mathrm{S}-\mathrm{R}$ association. There is evidence that the $\mathrm{S}-\mathrm{R}$ codes and modalities and the relative timing of the activations produced automatically and intentionally have strong impacts on the SRC effect. In sum, the phenomena and models for SRC present a relatively coherent picture in which response selection is a consequence of interactive activation from several sources and is affected by such variables as timing and S-R modalities. The number and nature of these interactions likely will be even more complex when two different tasks must be performed in close temporal proximity, as in the PRP paradigm.

\section{PSYCHOLOGICAL REFRACTORY PERIOD IN DUAL-TASK PERFORMANCE}

\section{Dual-Task Interference}

When two tasks are performed concurrently, interference between them usually occurs. Extensive research has been conducted to understand the mechanism that underlies this dual-task interference. Welford $(1952,1959)$ and Davis (1957) suggested that there is a single-channel process located in the central stage. Broadbent $(1958,1982)$ argued that there is a limitation on how much information the cognitive system can transmit at one time. Moray (1967) and Kahneman (1973) proposed that there is a general resource that must be drawn on to perform the two tasks. Kinsbourne and Hicks (1978) declared that performance declines when both tasks are processed within the same cerebral hemisphere, in comparison with different hemispheres. Navon and Miller (1987) attributed outcome conflicts to the processing required for one task conflicting with the processing required for the other task. The common feature of all these hypotheses is that they attribute dual-task interference to the competition of tasks for the use of a common processing mechanism or of the same resource.

A customary way to study dual-task interference is to present the stimuli (S1 and S2) for two tasks (T1 and T2) in rapid succession and require speeded responses to each 
( $\mathrm{R} 1$ and $\mathrm{R} 2$, respectively). The interval between the onsets of $\mathrm{S} 1$ and $\mathrm{S} 2$, termed the stimulus onset asynchrony (SOA), is varied, and RT is measured for each task (RT1 and RT2). A typical finding is that RT2 is delayed by several hundred milliseconds with respect to when the task is performed alone and increases as the SOA decreases. This PRP effect demonstrates a significant limitation in people's ability to perform two tasks in parallel.

By making an analogy to refractoriness in nerve fibers, Telford (1931) hypothesized that the delay in RT2 at the short SOA is due to a central refractory state after responding to S1. Smith (1967b) argued that if refractoriness were the cause of dual-task interference, the delay of RT2 should be constant and equal to the value of the refractory period up to a certain SOA and then should disappear when SOA increases beyond that point. In other words, the delay in RT2 should be constant, rather than decrease gradually as SOA increases, which is the typical finding. Additionally, Smith indicated, "There is no physiological evidence of refractoriness in any part of the nervous system" (p. 204).

\section{Influential Theoretical Accounts of PRP Effects}

Because the PRP effect appears to reflect a severe constraint in the ability to process two tasks in parallel, it has been the subject of intensive empirical and theoretical interest. Three currently influential theoretical accounts of the PRP effect are those of response-selection bottleneck, response-initiation bottleneck, and strategic response deferment. Comprehensive reviews of the PRP effect and evaluations of the relative adequacy of the alternative theories are provided by Meyer and Kieras (1997a, 1997b), Pashler (1994), Pashler and Johnston (1998), and Schweickert and Boggs (1984).

Response-selection bottleneck account. Pashler (1984) suggested that certain critical stages for both tasks cannot operate simultaneously. He took a similar approach to Welford (1952), who favored a single-channel account in which the PRP effect is attributed to an inability to perform the central operations for $\mathrm{S} 2$ at the same time as those for S1. Pashler (1984) argued more explicitly that the stage of response selection involves a bottleneck, in which the stimuli are processed in a sequential manner. In contrast, the processing prior or posterior to decision-related stages occurs in parallel for two tasks. The responseselection bottleneck (RSB) model assumes that the slowing of RT2 at short SOAs occurs because response selection for T2 cannot start until that for T1 has ended (see Figure 3 ). This causes a delay between the completion of perceptual processing of $\mathrm{S} 2$ and the beginning of response selection for T2. When SOA increases, response selection for $\mathrm{T} 1$ could be completed before response selection for $\mathrm{T} 2$ commences, and thus R2 can be selected immediately upon the identification of S2.

Pashler (1994, 1998) derived a number of predictions from the RSB model and provided evidence supporting it. These predictions were based on locus of slack logic, an extension of additive factors logic (Sternberg, 1969) in tasks involving concurrent processing. This logic, developed by Schweickert (1980), is based on critical-path scheduling, which allows both sequential and parallel processes to occur. It allows distinct predictions about the effects of T1 and T2 variables on RT2 as a function of where in processing a bottleneck occurs. The four major predictions Pashler $(1984,1998)$ derived for the RSB model involve the effects on RT2 of independent variables that influence the duration of stimulus identification (prebottleneck), response initiation (postbottleneck), or response selection (bottleneck) for T1 and T2. The first prediction is that an increase in the duration of stimulus identification or response selection for T1 should increase RT2 at short SOAs. Second, an increase in the duration of the postbottleneck
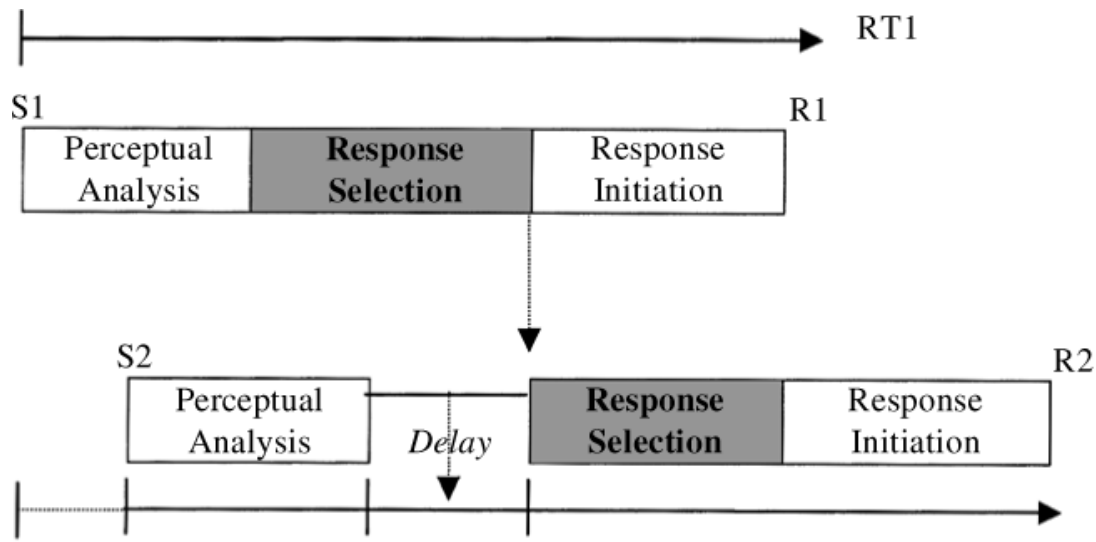

SOA

Figure 3. Pashler's response-selection bottleneck model for dual-task performance. The response-selection stage for Task 2 (T2) cannot begin until the response selection for Task 1 (T1) has been completed. S1, the first stimulus; S2, the second stimulus; R1, response to S1; R2, response to S2; RT1, reaction time for T1; RT2, reaction time for T2; SOA, stimulus onset asynchrony. 
response initiation in T1 will not increase RT2 because response selection for $\mathrm{T} 2$ can proceed along with response initiation for $\mathrm{T} 1$. The third prediction involves the effects of independent variables that influence the duration of prebottleneck processing in T2. An increase in the perceptual processing of S2 will have only a small effect on RT2 at short SOAs because the delay of response selection for $\mathrm{T} 2$ allows the perceptual processing time for S2 to be absorbed into the slack. However, at long SOAs, the increase in the perceptual processing time for T2 will delay all the processing after it, without being absorbed into the slack. Therefore, the variables affecting the prebottleneck stage of T2, such as stimulus intensity and display size, will produce an underadditive interaction with SOA in which the effect decreases as SOA decreases. The final prediction from the RSB model is that any variables affecting primarily the response-selection stage of $\mathrm{T} 2$ should have a constant effect on RT2 that is independent from SOA. Thus, an increase in the duration of response selection in $\mathrm{T} 2$ will increase RT 2 correspondingly at all SOAs. Therefore, variables affecting the response-selection stage for T2 will have an additive effect with SOA.

Pashler and Johnston (1989) confirmed the predicted underadditive interaction with SOA of a perceptual variable on S2. In their Experiment 1, subjects were asked to classify a tone as high or low pitched for T1 by making a keypress response with one hand; for T2, a single visual letter was identified by making a keypress response with the other hand. The visual intensity (or contrast) of the letters for T2, either white (high intensity) or gray (low intensity) against a dark background, was manipulated. The effect of S2 intensity was significantly larger at long SOAs than at short SOAs. This underadditive pattern of results is consistent with the RSB model, according to which the additional time to process a low-intensity $\mathrm{S} 2$ could be absorbed into the slack at short SOAs. Underadditive interactions also have been obtained for other perceptual variables such as display size (De Jong, 1993; Pashler, 1984).

Pashler and Johnston (1989) also obtained evidence consistent with the prediction of an additive effect of a responseselection variable with SOA: Repetition of S2 from the previous trial did not interact significantly with SOA. Pashler (1989) obtained additional evidence in support of the predicted additive effect with a different manipulation of response-selection difficulty. T2 was to identify the highest digit in the display by making one of four keypress responses (difficult task; Experiment 3) or vocal naming responses (easy task; Experiment 4). The keypress and vocal responses both showed a substantial PRP effect, with RT2 being $150 \mathrm{msec}$ slower in the manual response condition than in the vocal naming condition. Pashler interpreted the similarity of the PRP effects in these two experiments as "basically another case of response selection delay factors being additive with SOA" (p. 500), although there was a tendency for the PRP effect to be larger for the easy task $(210 \mathrm{msec})$ than for the difficult task $(192 \mathrm{msec})$.

Response-initiation bottleneck account. Several researchers have argued that the locus of the bottleneck is in the initiation of a response, rather than in the selection of a response. In contrast to the RSB model's prediction of additive effects of $\mathrm{T} 2$ response-selection variables with SOA on RT2, the response-initiation bottleneck model predicts underadditive interactions. Recently, Ivry, Franz, Kingstone, and Johnston (1998) concluded that the locus of the PRP effect for a callosotomized patient was in response initiation because he showed an underadditive interaction on RT2 of SOA and T2 S-R mapping.

The primary argument for a response-initiation bottleneck in normal adults was first made by Keele (1973), who interpreted the results obtained by Karlin and Kestenbaum (1968) as being evidence for such a bottleneck. Their subjects responded with a left-hand keypress to a visual digit for $\mathrm{T} 1$ and a right-hand keypress to a tone for T2. T2 complexity was varied, being either a one-choice (simple) or two-choice RT task. When T1 was a simple RT task, the difference in RT2 between simple and two-choice T2 tasks decreased from $84 \mathrm{msec}$ at long SOAs to $27 \mathrm{msec}$ at short SOAs. Similarly, when T1 was a two-choice RT task, the difference in RT2 between simple and two-choice T2 tasks decreased from $89 \mathrm{msec}$ at long SOAs to $39 \mathrm{msec}$ at short SOAs. The underadditive interaction of T2 complexity with SOA implies that response selection for T2 can occur in parallel with that for T1. Keele (1973) and others (e.g., De Jong, 1993) have cited Karlin and Kestenbaum's results as evidence that the bottleneck responsible for the PRP effect is not associated with response selection but with response initiation.

However, recent studies by Van Selst and Jolicœur (1997) and Schubert (1999), similar to that of Karlin and Kestenbaum (1968), do not support the response-initiation bottleneck interpretation. In Van Selst and Jolicœur's Experiment 1, T1 required left-hand keypresses to tones in a two-choice task. T2 was either a simple, two-choice, or threechoice right-hand keypress to a visual color patch. A comparison between the simple and two-choice tasks showed the difference of RT2 to decrease with decreasing SOA, as in Karlin and Kestenbaum's study. In contrast, the difference between two- and three-choice tasks for RT2 remained constant across SOA. Schubert's Experiment 3 showed a similar additive effect of SOA and two versus three choices. If there were a bottleneck at the responseinitiation stage, the difference of RT2 among two-choice and three-choice tasks, which is thought primarily to reflect response-selection difficulty, should decrease as SOA decreases. Van Selst and Jolicœur's Experiments 2 and 3 used the same tasks as did Karlin and Kestenbaum for T1 and $\mathrm{T} 2$ (i.e., visual T1 and auditory $\mathrm{T} 2$ ) and did not replicate the underadditive interaction between simple/two-choice task and SOA. Van Selst and Jolicœur concluded that the RSB model can account for the different patterns obtained in their simple and choice RT tasks. With the empirical evidence that detection (simple RT tasks) and discrimination (two- and three-choice tasks) require different amounts of perceptual processing (see Gottsdanker, 1979, and Schubert, 1999, for discussion), the RSB model would predict the underadditivity of SOA, with the difference of RT2 be- 
tween simple and two-choice tasks being found in their Experiment 1.

Van Selst and Jolicœur (1997) suggested that De Jong's (1993) multiple-bottleneck model also can provide an explanation for the underadditivity of SOA and the difference of RT2 between simple and two-choice RT tasks. The multiple-bottleneckmodel assumes that there is a responseinitiation bottleneck, in addition to a response-selection bottleneck, that imposes a further limitation on performing two responses in close succession. According to this model, there is a motor refractory period after the initiation of the first motor movement that prevents the initiation of another one. Therefore, response initiation for $\mathrm{T} 2$ is delayed if it occurs in temporal proximity to that for $\mathrm{T} 1$. The output interference also tends to be stronger when the two responses involve similar motor systems, as when manual responses are required for both tasks. Van Selst and Jolicœur explained that only the simple RT task for T2 was likely to be influenced by the response-initiation bottleneck because the response selection for T2 was extremely short and the initiation of R2 might be delayed by the motor refractory period following initiation of R1. However, in two- and three-choice tasks, the increase of responseselection processing in $\mathrm{T} 2$ should delay the initiation of $\mathrm{R} 2$ following execution of $\mathrm{R} 1$ so that it no longer coincides with the refractory period.

Schubert (1999) provided evidence that favors the RSB interpretation over the response-initiation bottleneck interpretation. He showed that the underadditive interaction with SOA for simple and two-choice tasks in Karlin and Kestenbaum (1968), De Jong (1993), and Van Selst and Jolicœur's (1997) Experiment 1 was a function of subjects' strategic preparation and anticipation in the simple RT task. In his Experiment 1, Schubert regarded responses faster than $150 \mathrm{msec}$ as anticipations. Anticipationsoccurred only at the longest, 800-msec SOA and were restricted to the simple RT task. An underadditiveinteraction between one versus two $\mathrm{S}-\mathrm{R}$ alternatives and SOA was obtained, but it was more pronounced when the simple RT task followed the two-choice task than when it preceded it. Schubert interpreted this outcome as indicating that subjects are less likely to use an anticipation strategy in the simple RT task at long SOAs when the task follows the two-choice task. Schubert attempted to eliminate anticipations in his Experiments 2 and 3 by having the stimulus for the simple RT task occur on only half of the trials. With this change in method, the interaction with SOA changed from underadditive to overadditive. Schubert's results, on the whole, are consistent with the RSB model and indicate that the underadditive pattern obtained by Karlin and Kestenbaum was due to anticipatory strategies that can be used to speed responding at long SOAs for a simple RT task but not for a choice RT task.

Although Pashler (1997) advocated response selection as the major bottleneck in processing, he pointed out the possibility of a response-initiation bottleneck's existing under some conditions, for example, when one of the two manual responses involves a sequential keypress response.
Pashler (1997) suggested that the limitation on response initiation is not the major concern and seems to contribute little to the PRP effect observed in most studies involving quick manual responses.

Strategic response-deferment account. Because the evidence has not been entirely consistent with either a response-selection or response-initiationlocus of the bottleneck, Meyer and Kieras (1997a, 1997b) suggested that the locus might change as a function of the subjects' strategies. This top-down generalization led them to develop a comprehensive architecture, the executive-process interactive control (EPIC) architecture, in which models for specific multiple-task situations could be developed. The model derived from the EPIC architecture that integrates empirical PRP findings and makes quantitative predictions for the PRP effect is called the strategic responsedeferment (SRD) model.

The EPIC architecture provides a structural informationprocessing framework with a fixed set of components that govern perceptual, cognitive, and motoric processing. It allows flexible scheduling strategies to be used in coping with processing limitations and in satisfying task priorities. Meyer and Kieras (1997a, 1997b) assumed that there is no limitation on how many response-selection rules can be involved during processing, which is contrary to the implication of the RSB model that only one rule at a time can be applied. Instead, Meyer and Kieras considered that a bottleneck is located at the motor processors, as is claimed by Keele (1973), and suggested that the manual and vocal motor processors constitute single-channel bottlenecks that allow only one response of a given mode to be produced at a time.

On the basis of the EPIC architecture, Meyer and Kieras (1997a) developed the SRD model, which incorporates a task-scheduling strategy to account for the PRP effect. They suggested that the perceptual processing of T2 can proceed concurrently with that of $\mathrm{T} 1$. The selection of R2 does not, however, need to wait until the selection of R1 has been completed, as Pashler (1984) hypothesized. Temporal overlapping of all stages of processing, except the motor-execution stage, for the two tasks is possible across SOA conditions. People have flexible control over the processing course of T2. This control is governed by an executive process that can lock out and unlock $\mathrm{T} 2$ between any two processing stages.

By applying this assumption to the PRP paradigm, the SRD model assumes that executive processes coordinate the progress of the two tasks by postponing or locking out one stage of T2 as a deferred mode until T1 is completed. The lockout might be located before the onset of stimulus identification, response selection, or movement production in T2, depending on relative task priorities and the subjects' strategic biases. For example, the emphasis on $\mathrm{T} 1$ in a PRP task might lead subjects to adopt a response-selection bottleneck scheduling strategy and, thus, produce a strategic rather than structural bottleneck. Because of how the executive process works, the processing of stimulus identification to response initiation for $\mathrm{T} 2$ might occur in three 
different sequences (see Meyer \& Kieras, 1997a, Figures 10-13). The decision of which sequence is taken depends on the SOA and the relative difficulty between $\mathrm{T} 1$ and $\mathrm{T} 2$.

According to the SRD model, the PRP effect is due to the shorter SOA's attenuating the lockout slack for T2 in the response-initiation stage. When the interval between onsets of $\mathrm{S} 1$ and $\mathrm{S} 2$ is short, $\mathrm{T} 2$ can be processed during most of the time that T1 is being processed. Schumacher et al. (1999) presented evidence that they interpreted as support of the SRD model's assumption that response selection for T2 can occur in parallel with that for T1. In Experiments 1 and 2, they varied the number of stimuli assigned to each of two keypresses, assuming that this manipulation affected response-selection difficulty for T2. The results of both experiments showed an underadditive interaction of T2 difficulty with SOA, with the RT difference between easy and difficult conditions being about $75 \mathrm{msec}$ less at the shortest SOA than at the longest. On the basis of their assumption that the manipulation of the number of $\mathrm{S} 2$ alternatives assigned to each response has its effect primarily on response selection, Schumacher et al. concluded on the basis of the underadditive interactions that response selection for T2 can occur in parallel with that for T1.

In contrast, Pashler and his colleagues (Levy \& Pashler, 2001; Ruthruff, Pashler, \& Klaassen, 2001) have provided evidence that they regard as favoring the structural view over the strategic view. Instead of using the standard PRP paradigm, both studies compared simultaneous dual-task performance with single-task performance. To equate the level of task preparation for the single-task trials with that of the dual-task trials, the task to be performed in the singletask blocks was uncertain until the stimulus occurred. In both studies, different input and output modalities were used for the two tasks in order to minimize peripheral interference, and the subjects were instructed to emphasize the two tasks equally. These procedures were adopted in order to create a situation in which the EPIC model would predict little interference because it attributes interference primarily to response initiation conflict and to strategies adopted when the response for one task is to be made before that for the other. Yet, three of the four experiments in the two articles showed dual-task interference, which the authors attributed to a structural, central bottleneck. The debate as to whether there is a structural or strategic responseselection bottleneck is unresolved at this time.

\section{Summary}

PRP effects can be observed in dual-task performance with various stimulus and response manipulations. When successive stimuli require different responses, delays of RT2 at short SOAs are almost invariably found. Bottleneck accounts have been advanced to explain the PRP effect primarily in terms of a fixed bottleneck that can only process two tasks serially. The response-selection bottleneck account locates the bottleneck at response selection, whereas the response-initiationbottleneck account locates it at response initiation. In spite of the argument regarding which stages of two tasks are processed sequentially or in parallel, both accounts are in agreement with the hypothesis that the greater the temporal overlap between the two tasks, the longer the resulting delay of RT2.

Yet, most PRP studies have favored the RSB account, which assumes that the response-selection bottleneck is the sole cause of the PRP effect. The supporting findings have shown that perceptual variables typically have underadditive interactions with SOA, whereas response-selection variables often have additive effects with SOA. Recently, it has been argued that subjects' strategies play a role in determining the locus of the bottleneck. In contrast to the RSB account that assumes fixed processing limitations, the EPIC model attributes the PRP effect to deferment of response initiation in $\mathrm{T} 2$ with a flexible control of strategy, sometimes a lockout of R2 being selected until selection of R1 is completed. Whether the processing limitation in response selection is structural or strategic remains to be resolved.

\section{COMPATIBILITY IN DUAL-TASK PERFORMANCE}

\section{Can PRP Effects be Eliminated with Ideomotor Compatible Tasks?}

There has been controversy in the dual-task literature as to whether the two tasks are processed in parallel or sequentially (e.g., Allport, Antonis, \& Reynolds, 1972; Keele, 1973; McLeod, 1977; Pashler, 1984, 1989). It has been suggested that the manner in which the processing occurs might depend on the nature of the tasks involved (Greenwald \& Shulman, 1973; McLeod \& Posner, 1984; Posner, 1966; Smith, 1967a). More specifically, Greenwald (1970a, 1970b, 1972) has argued that two tasks can be time shared perfectly and dual-task interference eliminated when both tasks are ideomotor compatible. He distinguished ideomotor compatibility from SRC, using SRC to refer to situations in which "natural or highly learned associations are involved" and ideomotor compatibility to situations in which the "stimulus resembles sensory feedback from the response" (Greenwald \& Shulman, 1973, p. 70). Greenwald (1970b) proposed an ideomotor theory and suggested that, when S-R sets are ideomotor compatible, a response code is activated directly by the stimulus. Accordingly, when two tasks are ideomotor compatible, $\mathrm{R} 1$ and $\mathrm{R} 2$ can be selected directly, bypassing the limitedcapacity response-selection stage.

To demonstrate the role of ideomotor compatibility in dual-task interference, Greenwald (1972) varied the degree of ideomotor compatibility by combining two types of spatial stimuli and responses. An arrow pointing to the left or right was presented in the center of a screen while the word "left" or "right" was presented simultaneously through headphones. Two types of responses, moving a switch to the left or right and saying "left" or "right," were combined with the two stimulus types to yield different degrees of ideomotor compatibility. In the low ideomotor compati- 
bility condition, subjects moved the switch to the left or right in response to the auditory word left or right while they said "left" or "right" in the direction in which the arrow pointed. In the high ideomotor compatibility condition, subjects said "left" or "right" in response to the auditory word while they moved the switch to the left or right depending on the arrow direction. The high ideomotorcompatibility condition showed efficient performance that conformed closely to the predictions of a parallel-decision model, but the low ideomotor compatibility condition did not.

Greenwald and Shulman (1973) applied the concept of ideomotor compatibility to the PRP effect and suggested that the effect could be eliminated when both tasks are highly ideomotor compatible. They examined the roles of SRC and ideomotor compatibility in the PRP effect with various $\mathrm{S}-\mathrm{R}$ relations. For T1, a left or right movement of a switch was always made to a visual stimulus, which could be the word left or right or a left- or right-pointing arrow. For T2, the vocal response, "A" or "B" in one condition and "one" or "two" in another condition, was always made to an auditory stimulus "A" or "B." Greenwald and Shulman identified the conditions of movement responses to arrow directions and of verbal responses to the letters $A$ and $B$ as ideomotor compatible tasks, and the conditions of movement responses to the words left and right and verbal responses "one" and "two" to the auditory stimuli "A" and "B" as S-R compatible tasks (see Figure 4).

In Greenwald and Shulman's (1973) Experiment 1, S1 and S2 were presented with a 0-, 100-, 200-, 300-, 500-, or 1,000 -msec SOA, and the instructions stressed that S2 always followed S1. RT2 showed a substantial PRP effect of approximately $100 \mathrm{msec}$ for all conditions, including the condition in which both tasks were ideomotor compatible. Greenwald and Shulman reasoned that their instructing subjects that S2 always followed S1 caused them to adopt a strategy of responding to $\mathrm{S} 1$ before $\mathrm{S} 2$, artificially producing delays in RT2. Therefore, in their Experiment 2, subjects were told that the two stimuli would be most often presented simultaneously, and only the 0-, 100-, 200-, and 1,000 -msec SOAs were included. In this case, the condition for which both tasks were ideomotor compatible showed no PRP effect for RT2 alone or the average of RT1 and RT2.

Although the data from Greenwald and Shulman's (1973) Experiments 1 and 2 were not in agreement and suggest, at a minimum, that instructions play a role in eliminating the PRP effect, they stated in their abstract that the PRP effect "was eliminated when both of the tasks were ideomotor compatible" (p. 70). Most subsequent citations of their study have also stated that the results demonstrated that the PRP effect was eliminated with two ideomotor compatible tasks (e.g., De Jong, 1995; Meyer \& Kieras, 1997a; Pashler, 2000). Lien, Proctor, and Allen (2002) questioned the generalization that the PRP effect is eliminated with two ideomotor compatible tasks because of the discrepancy in results between Greenwald and Shulman's Experiments 1 and 2 . We noted that the reason for the discrepant results is not obvious because the designs of those two experiments differed in several potentially crucial respects (the aforementioned differences in instructions and SOAs, as well as the inclusion of single-task blocks in Experiment 2 but not in Experiment 1). We conducted a series of experiments, using the same tasks and instructions as those in Greenwald and Shulman's Experiment 2, with each experiment being a progressively closer approximation to their exact method: In our Experiment 1, we used the six SOAs from Greenwald and Shulman's Experiment 1; in Experiment 2, we used the four SOAs of their Experiment 2; in Experiment 3, we also included single-task blocks, as in Greenwald and Shulman's Experiment 2; in Experiment 4, we presented the arrow stimuli to the left or right of the screen, as in their study. In all cases, a substantial PRP effect was evident for the condition in which the two tasks were ideomotor compatible.

A study by Brebner (1977) also obtained a PRP effect for two ideomotor compatible tasks. In Brebner's experiment, subjects placed the tips of their index and middle fingers of each hand on solenoid-operated response buttons. S1 and S2 were stimulation of a finger on the left and right hands, respectively, produced by upward pressure on each fingertip from the solenoid located underneath it. R1 was to press the button corresponding to the stimulated finger on the left hand, whereas R2 was to

\begin{tabular}{|c|c|c|c|}
\hline Tasks & Events & $\begin{array}{c}\text { Stimulus-Response } \\
\text { Compatible Tasks (SR) }\end{array}$ & $\begin{array}{c}\text { Ideomotor Compatible Tasks } \\
\text { (IM) }\end{array}$ \\
\hline \multirow{2}{*}{1} & Stimulus 1 (Visual) & If "LEFT" move switch left & If " "move switch left \\
& Response 1 (Manual) & If "RIGHT" move switch right & If " \\
\hline \multirow{2}{*}{2} & Stimulus 2 (Auditory) & If "A" say "one" switch right \\
& Response 2 (Vocal) & If "B" say "two" & If "A" say "A" \\
& & If "B" say "B" \\
\hline
\end{tabular}

Figure 4. Greenwald and Shulman's (1973) tasks and procedures in their Experiment 1. 
press the button corresponding to the stimulated finger on the right hand. Five SOAs, ranging from 100 to $300 \mathrm{msec}$, were intermixed within a block. Five of 13 subjects showed evidence of grouping their responses, because RT1 increased with SOA. A significant PRP effect of $140 \mathrm{msec}$ was obtained for the subjects who did not adopt a grouping strategy, and the PRP effect averaged 105 msec across all subjects.

Greenwald's (1970a, 1970b) concept of ideomotor compatibility entails the assumption that $\mathrm{S}-\mathrm{R}$ translation is not needed for ideomotor compatible tasks because the stimulus is identical to the response code. An implication of this view is that there should be no PRP effect when only one of the two tasks is ideomotor compatible. However, this implication has not been supported in any dual-task study of which we are aware. ${ }^{2}$ A study by McLeod and Posner (1984) is often cited as showing no dual-task interference between a primary task, for which one of two keys was pressed in order to indicate whether a pair of successively presented visual letters was the same or different, and a secondary probe task of saying "up" or "down" to the auditory word up or down. However, they described their results as equivocal on this issue because when the probe stimulus was presented in close temporal proximity to the second of the two visual letters, probe RT was elevated by $22 \mathrm{msec}$ on average. Both of Greenwald and Shulman's (1973) experiments showed a PRP effect when one task was ideomotor compatible and the other was S-R compatible, as did all of Lien, Proctor, and Allen's (2002) experiments, which closely replicated the methods of Greenwald and Shulman's study (see also Kantowitz \& Knight, 1976, and Klapp, Porter-Graham, \& Hoifjeld, 1991, for similar results with continuous tapping and shadowing tasks). Across the experiments reported by Greenwald and Shulman and by Lien, Proctor, and Allen (2002), the PRP effect tended to be larger when T2 was ideomotor compatible than when $\mathrm{T} 1$ was, suggesting that although serial response selection is still required for an ideomotor compatible task, it is faster than for a nonideomotor compatible task.

In summary, of the experiments in which two ideomotor compatible tasks were performed together in the PRP paradigm, only Greenwald and Shulman's (1973) Experiment 2 showed no evidence of a PRP effect. This outcome was not replicated in their Experiment 1, nor in Lien, Proctor, and Allen's (2002) study that used the same instructions and closely approximated Greenwald and Shulman's experimental designs. A substantial PRP effect also occurred for two ideomotor compatible tasks in Brebner's (1977) study that required presses of stimulated fingers. Not only is the PRP effect evident when both tasks are ideomotor compatible, but it is also found when an ideomotor task is paired with another nonideomotorcompatible task. If the PRP effect has its basis in response selection, the view that ideomotor compatible tasks bypass response selection is not supported by the evidence. This view can still be maintained, however, if one assumes that the locus of the PRP effect is subsequent to response selection.

\section{Can PRP Effects With Compatible Tasks Be Eliminated Through Practice?}

An issue regarding the PRP effect that is pertinent to alternative models of response selection is whether the effect can be eliminated with practice. The RSB model implies that the PRP effect should not be eliminated with practice: The effect should diminish as response selection for T1 becomes more efficient, but a delay for RT2 should be evident at short SOAs even with extended practice because response selection for $\mathrm{T} 2$ cannot begin until that for T1 is completed. Several studies have shown that the PRP effect is remarkably resistant to extinction with practice (Davis, 1957, 1959; Keele, 1986; Morill, 1957), as implied by the RSB model.

Gottsdanker and Stelmach (1971) attempted to eliminate the PRP effect by giving a single subject extended practice with two $\mathrm{S}-\mathrm{R}$ compatible tasks. Two successive lights were presented as S1 and S2 on the upper surface of cylindrical levers operated by the left and right hands. The subject was required to move each lever toward or away from himself, depending on which half of the surface was lit. The subject practiced for 87 days with a constant 100msec SOA, with RTs attaining asymptotic levels within the first 47 days. For the remaining 40 days, RT2 was 20-25 msec slower than the RT for single-task control conditions. In other words, the subject showed only a small PRP effect but was unable to eliminate it. Beginning on Day 88 and continuing for 22 days, SOA varied randomly among the values of 50, 100, 200, 400, and 800 msec. In these varied SOA conditions, RT 2 was $40 \mathrm{msec}$ slower at the 50-msec SOA than at the 800-msec SOA, indicating a PRP effect. Interestingly, for the 100-msec SOA in the practice sessions, RT2 did not increase in the varied SOA conditions and, atypically, was faster than RT2 at the 200-msec SOA. Gottsdanker and Stelmach drew two conclusions. First, the PRP effect can be reduced with extensive practice, but not eliminated entirely. Second, the reduction of the PRP effect with extensive practice is specific to the SOA used in practice. The PRP effect reappeared when varied SOAs were employed after the practice sessions in which a certain SOA was used.

Several other studies also showed little evidence that dualtask interference is eliminated, or in some cases even reduced much, by extensive practice (e.g., Karlin \& Kestenbaum, 1968, 3-7 days of practice; Van Selst \& Jolicœur, 1997, Experiment 2, 18 days of practice). However, Van Selst, Ruthruff, and Johnston (1999) questioned the generality of the conclusion that the PRP effect cannot be eliminated with practice, noting that most extendedpractice PRP studies required manual responses for both tasks. The PRP effect obtained with a small amount of practice is larger when the responses for both tasks are manual than when only one response is (De Jong, 1993; Lien $\&$ Proctor, 2000; Pashler, 1990). One explanation for why the PRP effect is larger when both responses are manual is that there is a bottleneck at the response-initiation stage (De Jong, 1993). If this bottleneck is resistant to practice, the PRP effect might remain for manual-manual re- 
sponse combinations but not for vocal-manual response combinations.

In an attempt to avoid response conflicts, Van Selst et al. (1999) conducted PRP experiments that used a vocal response ("high" or "low") to the pitch of an auditory tone as T1 and a manual keypress to a visual alphanumeric character (from the letters $A, B, C, D$, and the numbers 1 , 2,3 , and 4 ) as T2. For half of the subjects, the letters were mapped compatibly to responses (i.e., in alphabetic order onto the four response keys from left to right) and the digits incompatibly to responses (i.e., in scrambled order onto the four response keys). For the other half of the subjects, the digits were mapped compatibly to the responses and the letters were mapped incompatibly. This type of manipulation primarily allows rule-based translation to be used for compatible mapping but not for incompatible mapping. Through 36 sessions of practice (one per day), 5 out of the 6 subjects showed a dramatic decline in the PRP effect, from $350 \mathrm{msec}$ early in practice to about $40 \mathrm{msec}$ late in practice, with 1 subject showing no PRP effect. The results suggest that extensive practice leads to a substantial decrease in dual-task interference when the tasks require different response modalities. However, a small but significant PRP effect was still evident for the 5 subjects after practice, implying that the PRP effect is a robust phenomenon.

More interestingly, Van Selst et al. (1999) also examined the PRP effect as a function of RT1 across practice sessions and revealed a close one-to-one relation (a slope of 1.0) between the decrease of RT1 and the decrease of the PRP effect across sessions. Van Selst et al. interpreted this relation as supporting "bottleneck models in which practice primarily served to shorten the duration of central stages: The earlier Task 1 central operations finish, the less time Task 2 central operations must wait" (p. 1280). Moreover, they also found that the compatibility effect of T2 $\mathrm{S}-\mathrm{R}$ mapping, as most studies have shown, was relatively constant across SOAs for all practice sessions but with a dramatic reduction in the magnitude of the effect from early to late in practice. The results of Van Selst et al.'s study support the conclusion that the PRP effect is due to a response-selection bottleneck. Even after extensive practice, the bottleneck in the response-selection stage still remained, thus resulting in the PRP effect.

Ruthruff, Johnston, and Van Selst (2001) conducted three additional experiments with 5 of the subjects from Van Selst et al.'s (1999) study. In Experiments 1 and 2, the $\mathrm{S}-\mathrm{R}$ modality relations of the previous study were maintained, but the specific task was changed for T1 in Experiment 1 and T2 in Experiment 2. In Experiment 1, T1 was a tone-comparison task for which subjects responded "same" or "differ" vocally to the pitch of two tones. In Experiment 2, T2 was a visual letter-identification task for which subjects made left or right keypresses with their right hands regarding the identity of a letter. Consistent with Van Selst et al.'s conclusion that the reduction of the PRP effect with practice is due to faster performance of T1, Ruthruff et al. found that the PRP effect was smaller when $\mathrm{T} 1$ was the task that had been highly practiced in the earlier study than when T2 was. In their third experiment, they used the same tasks as those in Van Selst et al.'s study, except that the responses to the tones for $\mathrm{T} 1$ were keypresses made by the left hand, rather than vocalizations. In this case, a large PRP effect was evident in the initial session, and, although it decreased across sessions, the decrease was not as much as in the earlier study in which the T1 responses were vocal. Thus, a modality distinction between the two tasks allowed a greater reduction of the PRP effect with practice, but the effect was not eliminated in either case.

\section{Is There Cross-Talk Between the Two Tasks?}

Pashler's (1984) RSB model, as well as most other bottleneck models, depicts the processing of T1 and T2 in a PRP paradigm as occurring in two parallel, noninteractive streams. The only effect of $\mathrm{T} 1$ on performance of $\mathrm{T} 2$ is that response selection of T1 delays the onset of that of $\mathrm{T} 2$ at short SOAs. The model does not specify any relation between response selection for T1 and T2 other than that both cannot occur at the same time. Particularly, the translation processing of $\mathrm{S} 2$ to $\mathrm{R} 2$, including the $\mathrm{S}-\mathrm{R}$ mapping that is in effect for $\mathrm{S} 2$ and the specific $\mathrm{T} 2$ translation processing performed on a particular trial, should not have any impact on the translation processing of $\mathrm{S} 1$ to $\mathrm{R} 1$.

Based on the fact, discussed in the Pure and Mixed Spatial Mappings subsection for SRC, that RT is slowed, particularly for $\mathrm{S}-\mathrm{R}$ compatible mapping, when compatible and incompatible mappings are mixed (e.g., Duncan, 1977b), one would expect that T2 mapping would affect performance of T1, and vice versa. Duncan (1979) demonstrated that this in fact is the case by using a PRP paradigm in which the mappings for T1 and T2 were consistent or inconsistent. In his Experiment 2, subjects performed three-choice spatial reaction tasks with the left hand (T1) and the right hand (T2). For each task, the mapping was to press the corresponding key or the mirror opposite key. The PRP effect was evident for all mapping conditions, but the most interesting finding was that RT1 was elevated when mapping for $\mathrm{T} 2$ was inconsistent with that for $\mathrm{T} 1$, compared with when the two mappings were consistent. In fact, when paired with the opposite mapping for T2, RT for the compatible T1 mapping was increased to the level of that for the incompatible T1 mapping. Similar results were evident for RT2. Thus, the mapping that is in effect for one task apparently affects how the response for the other task is selected.

Duncan (1979) noted that subjects made more errors for both T1 and T2 when the mappings for the two tasks were inconsistent than when they were consistent. Errors to the left or right stimuli for each task could be classified as adjacent (by pressing the center key) or as transformational (e.g., by incorrectly pressing the far left key to the right stimulus if the mapping was corresponding or the far right key to the right stimulus if the mapping was opposite). For both $\mathrm{T} 1$ and $\mathrm{T} 2$, the translational errors accounted entirely for the higher error rate when the mappings were inconsistent. Duncan (1979) interpreted this result simi- 
larly to the way he interpreted the single-task, mixedmapping experiments-that is, a decision about which mapping rule is appropriate must be made when two different rules are in effect. More generally, the finding indicates that the mapping appropriate for one task might be misapplied to the other task.

Even stronger evidence that response selection is performed concurrently for the two tasks is provided by several PRP studies that have shown correspondence effects between tasks for both RT1 and RT2. Way and Gottsdanker (1968, Experiment 1) used a pair of two-choice tasks for which subjects were required to move levers with the left hand for $\mathrm{T} 1$ and the right hand for T2. The stimuli for each task were presented by illuminating one half of the flat upper surface of the lever, and the lever was to be moved in the direction corresponding to the half that was lit. Two display-control arrangements were tested, one for which the orientations of stimulus and response dimensions were parallel for the two tasks and one for which they were perpendicular. For the parallel arrangement, the direction of movement for T1 and T2 was toward or away from the subject, as signaled by lighting the upper or lower half of the respective lever. For the perpendicular arrangement, the direction of movement for T1 was toward or away from the subject, but that for T2 was to the left or right, as signaled by lighting the left or right half of the right lever. The response directions for $\mathrm{T} 1$ and $\mathrm{T} 2$ could be the same or opposite in the parallel arrangement and were unrelated (e.g., away for T1 and left for T2) in the perpendicular arrangement. The interval between the presentations of the two signals was either 100 or 900 msec.

Way and Gottsdanker (1968) obtained PRP effects of similar size for the parallel $(68-\mathrm{msec})$ and perpendicular (75-msec) orientations and found no difference in overall RT between the two conditions. Yet, within the parallel orientation, the PRP effect was larger when the response directions of the two tasks were opposite $(81 \mathrm{msec})$ than when they were the same $(54 \mathrm{msec})$. This difference in the magnitude of the PRP effect was due primarily to a spatial correspondence effect at the short SOA: RT2 was $21 \mathrm{msec}$ shorter when the response directions were the same for both tasks than when they were different. Moreover, RT1 also showed a correspondence effect at the short SOA, with RT1 being $14 \mathrm{msec}$ shorter when the response directions for the tasks were the same rather than different. The fact that RT1 was affected by the spatial correspondence of the stimuli and responses for the two tasks is particularly important because it indicates that some aspect of the processing for $\mathrm{T} 2$ influenced the processing for $\mathrm{T} 1$.

Way and Gottsdanker's (1968) Experiment 2 differed from their Experiment 1 in the use of stimuli that were the same for the away-toward and left-right movement conditions. For all tasks, the lever surface was divided along the negative diagonal so that the stimuli were upper right and lower left. Thus, the upper right stimulus was used to signal away or right and the lower left stimulus to signal toward or left in the respective conditions. The results replicated those of their Experiment 1. Most important, the parallel arrangement showed similar spatial correspondence effects at the short SOA, with the effect's being larger for RT2 $(32 \mathrm{msec})$ than for RT1 $(18 \mathrm{msec})$. The use of the same stimuli for the perpendicular orientation allowed Way and Gottsdanker to examine correspondence effects for the stimuli with the perpendicular arrangement. With that arrangement, there was a small correspondence effect at the short SOA for RT2 (13 msec) but essentially no difference for RT1 $(2 \mathrm{msec})$. The fact that the stimulus relations were the same for the parallel and perpendicular orientations, but the correspondence effect was absent for RT1 (and reduced for RT2) with the perpendicular orientation, indicates that the effects of T2 on RT1 were not primarily due to the correspondence relation between $\mathrm{S} 1$ and S2. Rather, the stimuli for T2 needed to be assigned to the same response orientation as for $\mathrm{T} 1$ in order for a correspondence effect on RT1 to occur.

Hommel (1998) also reported cross-task correspondence effects, indicating considerable interaction in the processing of the two tasks. In his Experiment 1, the stimuli were the letters $H$ or $S$ in red or green color. Subjects were to make keypress responses with their right or left hands to stimulus color and vocal "left"-"right" responses to letter identity. They were required to make the manual response (R1) first and then the vocal response (R2). RT1 was 75 msec faster and RT2 95 msec faster when R1 and R2 corresponded than when they did not. Experiment 2 was similar to Experiment 1, except that the R2 was the word red or green. In Experiment 2, the correspondence was between S1 (stimulus color) and R2 (color-naming responses). Again, correspondence effects were evident for both tasks, with RT1 being $104 \mathrm{msec}$ faster and RT2 $161 \mathrm{msec}$ faster when S1 and R2 corresponded than when they did not. The design of Experiment 4 was similar to that of Experiment 2 , except that the subjects were required to withhold the vocal responses for T2 until the stimulus offset, $1,500 \mathrm{msec}$ after its onset. The manual responses for $\mathrm{T} 1$ showed a $29-\mathrm{msec}$ correspondence effect, indicating that the effect of R2 on RT1 did not depend on R2's being performed in close temporal proximity to $\mathrm{R} 1$.

Hommel's (1998) Experiment 3 was similar to his Experiment 2, but he used a standard PRP procedure in which the stimulus information for the two tasks was presented in distinct objects, and SOA was varied. A red or green rectangle appeared on the center of the screen as S1. After an SOA of 50, 150, or $650 \mathrm{msec}, \mathrm{S} 1$ was replaced by the same color of a stimulus letter $H$ or $S$ that served as S2. Subjects responded, as in Hommel's (1998) Experiment 2, by pressing a left or right key to the color of the rectangle and saying "red" or "green" to the letter identity. The results of Experiment 3 showed a typical PRP effect of approximately $250 \mathrm{msec}$ for RT2. In addition, there was a correspondence effect between S1 and R2 at the 50-msec SOA for both RT1 $(28 \mathrm{msec})$ and RT2 $(63 \mathrm{msec})$. Thus, the S1-R2 correspondence effects occurred in a standard PRP task, although they were smaller in magnitude than those found when responses were made to two simultaneously presented dimensions of a stimulus. 


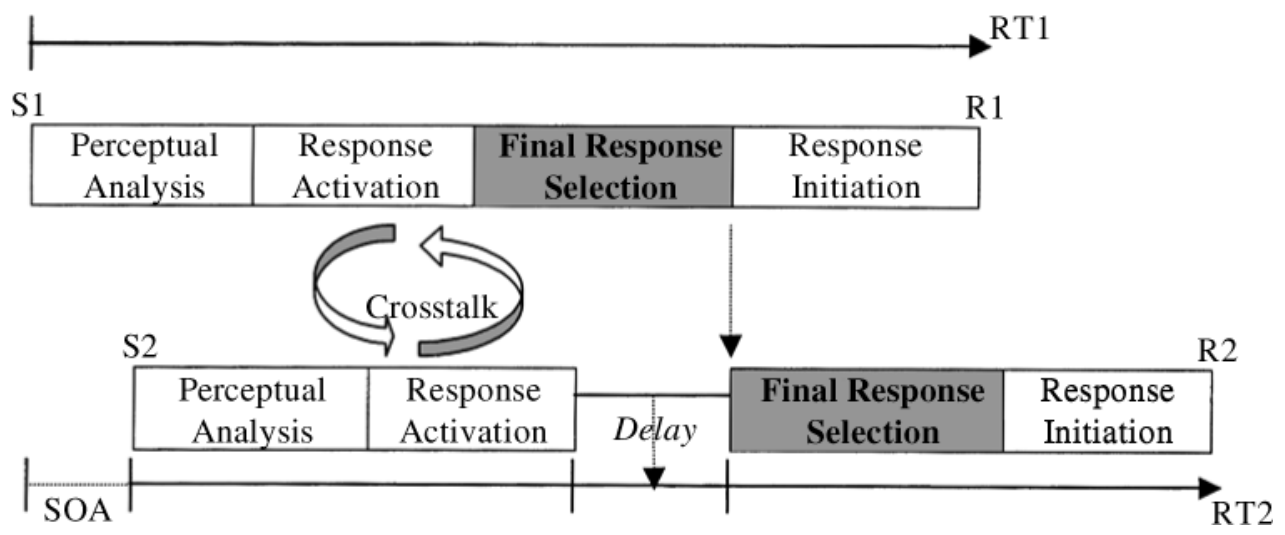

Figure 5. The two response-selection components approach proposed by Hommel (1998). The response activation of Task 2 can be processed with that of Task 1 in parallel and allow cross-talk to affect the processing for both tasks. The final response selection of $\mathrm{T} 2$ cannot be made until the final response decision of $T 1$ has been completed. S1, the first stimulus; S2, the second stimulus; R1, response to S1; R2, response to S2; RT1, reaction time for T1; RT2, reaction time for T2; SOA, stimulus onset asynchrony.

According to the RSB model, the central processing of $\mathrm{R} 2$ is delayed during the response-selection of $\mathrm{T} 1$ at short SOAs and should have no effect on RT1. However, Hommel's (1998) results suggest that the response for T2 was activated to some extent while response selection was still being performed for T1. Hommel concluded that the translation of S2 into response activation was not delayed until response selection for T1 was completed, as the RSB model would suggest. Instead, the $\mathrm{S}-\mathrm{R}$ translation for both tasks could occur concurrently. Therefore, the correspondence relation between R 1 and R2 affected not only RT 2 but also RT1 at short SOAs. However, the response selection for T1 might have been completed before the presentation of $\mathrm{S} 2$ at long SOAs. Thus, the correspondence effect decreased as SOA increased.

To reconcile the correspondence effect in dual-task performance with the RSB model, Hommel (1998) specified $\mathrm{S}-\mathrm{R}$ translation and final response selection as two distinct stages. He argued that $\mathrm{S}-\mathrm{R}$ translation occurs automatically and in parallel for $\mathrm{T} 1$ and $\mathrm{T} 2$, with the final response-selection decision's being serial (see Figure 5). Interestingly, Pashler (1993) suggested a similar view in an attempt to resolve findings indicating that multiple stimuli can simultaneously activate a single response (a property called coactivation; Miller, 1982) with the evidence for the RSB model in the PRP paradigm. He stated,

If memory retrieval involves establishing a characteristic pattern of activity in a large ensemble of neurons, then having multiple cues available may cause the appropriatefinal pattern to emerge more quickly. However, the neuronal pattern that enables one response to be performed may not be the pattern that enables other responses to be performed at the same time. Thus, the selection of two different responses would constitute a bottleneck even though coactivation would also occur. (p. 55)

If the bottleneck is located after S-R translation, as Hommel and Pashler have proposed, locus-of-slack logic predicts that the Simon effect on T2, where the irrelevant S2 location is automatically activated and decays rapidly, would be underadditive with the effect of SOA, as was found in the studies of McCann and Johnston (1992) and Lien and Proctor (2000). According to this approach, the response codes for $\mathrm{T} 2$ can receive some degree of activation before $\mathrm{R} 1$ is selected. Thus, it allows cross-talk between the two tasks, and the processing of T2 shows backward correspondence effects on RT1 at short SOAs.

Examination of cross-talk correspondence effects in Lien and Proctor's (2000) PRP study also indicates that there is considerable interaction of the spatial information sources from the two tasks that affected both RT1 and RT2 (see Table 2 for the possible sources of T1-T2 correspondence effects). In Experiments 2 and 3, T2 involved a left or right keypress with one hand in response to a left- or right-pointing arrow. The arrow was presented to the left or right of fixation, with stimulus location being irrelevant. For half of the subjects, the mapping of arrow direction to responses was compatible, whereas for the other half, it was incompatible. T1 required a left or right keypress with the other hand to a high- or low-pitch tone in Experiment 2 and to a visual letter $M$ or $T$ on the center of the screen in Experiment 3. SOAs of 50, 150, 300, and

Table 2

The Possible Sources of Correspondence Effects for Task 1 (T1) and Task 2 (T2) in a PRP Paradigm

\begin{tabular}{|c|c|c|c|c|c|}
\hline \multirow[b]{3}{*}{ Task } & \multicolumn{5}{|c|}{ Overlapping Dimensions } \\
\hline & \multirow{2}{*}{\multicolumn{2}{|c|}{$\begin{array}{c}\text { Within-Task } \\
\begin{array}{c}\text { Stimulus-Response } \\
\text { Dimensions }\end{array}\end{array}$}} & \multicolumn{3}{|c|}{ Between-Task } \\
\hline & & & $\begin{array}{r}\text { Stimulus } \\
\text { Dime }\end{array}$ & $\begin{array}{l}\text {-Response } \\
\text { nsions }\end{array}$ & $\begin{array}{c}\text { Response-Response } \\
\text { Dimensions } \\
\end{array}$ \\
\hline $\mathrm{T} 1$ & $\mathrm{~S} 1 \mathrm{r}-\mathrm{R} 1$ & S1ir-R1 & $\mathrm{S} 2 \mathrm{r}-\mathrm{R} 1$ & S2ir-R1 & $\mathrm{R} 2-\mathrm{R} 1$ \\
\hline $\mathrm{T} 2$ & $\mathrm{~S} 2 \mathrm{r}-\mathrm{R} 2$ & S2ir-R2 & $\mathrm{S} 1 \mathrm{r}-\mathrm{R} 2$ & S1ir-R2 & $\mathrm{R} 1-\mathrm{R} 2$ \\
\hline
\end{tabular}

Note-S1r, the relevant information of the first stimulus; S 1ir, the irrelevant information of the first stimulus; $S 2 r$, the relevant information of the second stimulus; S2ir, the irrelevant information of the second stimulus; R1, the first response; R2, the second response. 
$800 \mathrm{msec}$ were used to vary the degree of temporal overlap between the two tasks. Of concern in Lien and Proctor's (2000) experiments were multiple cross-talk spatial correspondence effects, those of R2-R1 and S2-R1 on RT1 and of R1-R2 and S2-R2 on RT2.

For the compatible mapping group, RT1 was faster when the location of $\mathrm{R} 2$ corresponded with that of $\mathrm{R} 1$ than when it did not, particularly at short SOAs (at 50-msec SOA, $69 \mathrm{msec}$ in Experiment 2 and $58 \mathrm{msec}$ in Experiment 3). S2 location also tended to produce a correspondence effect with R1 location at short SOAs (at 50-msec SOA, $32 \mathrm{msec}$ in Experiment 2 and $11 \mathrm{msec}$ in Experiment 3). RT2 also showed a correspondence effect: Responses were faster when R1 and R2 locations corresponded than when they did not, particularly at short SOAs (at 50-msec SOA, $55 \mathrm{msec}$ in Experiment 2 and $60 \mathrm{msec}$ in Experiment 3). S2 location also produced a correspondence effect with R2 location (i.e., a Simon effect of $24 \mathrm{msec}$ overall in Experiment 2 and $44 \mathrm{msec}$ in Experiment 3), with this within-task effect being larger at the longer SOAs. At short SOAs, the effect of R1-R2 correspondence on RT2 was stronger than the Simon effect on RT2 produced by S2 location. Given the assumption of the RSB model that selection of R2 does not start until the selection of $\mathrm{R} 1$ has been completed, the results in Lien and Proctor's (2000) study are inconsistent with the implication that RT1 should not be affected by selection of R2. In sum, the finding of R1-R2 correspondence effects on RT1 implies that the response selection of $\mathrm{T} 2$ can occur in parallel with that for T1, to some extent, and interact with it, when the two tasks overlap in time at short SOAs.

For the incompatible mapping group, R1-R2 correspondence had an effect on RT1. At the 50-msec SOA, RT was $45 \mathrm{msec}$ faster in Experiment 2 and $54 \mathrm{msec}$ in Experiment 3 when the responses corresponded than when they did not. RT2 also tended to show a correspondence effect, particularly at the 50-msec SOA ( $27 \mathrm{msec}$ in Experiment 2 and $13 \mathrm{msec}$ in Experiment 3), although it was smaller than for the compatible mapping group. The correspondence effects produced by S2 on RT1 were negligible, and those on RT2 tended toward a small, reverse Simon effect favoring the noncorresponding responses. The correspondence effects obtained on RT1 for the incompatible mapping group are important because they show that a similar magnitude of correspondence effect occurs when the mapping of arrows to responses is changed and that it follows the response relationship and not the relationship of arrow direction to R1.

Logan and Schulkind (2000) extended the examination of cross-task correspondence effects to semantic category retrieval tasks in a PRP paradigm. In their Experiment 1, subjects performed a letter-digit category-discrimination task for both T1 and T2. For T1, subjects were required to respond to a letter or digit stimulus above fixation by pressing the index or middle finger of the right hand. For $\mathrm{T} 2$, they responded in a similar manner to a stimulus below fixation, using the index and middle fingers of the left hand. The assignment of letters and digits to the specific keypresses was counterbalanced within tasks and between tasks across subjects. The correspondence effects evaluated by Logan and Schulkind thus did not involve the R1$\mathrm{R} 2$ location relation but the category relation for the two tasks. A large PRP effect was obtained, with overall correspondence effects of $133 \mathrm{msec}$ for RT1 and $217 \mathrm{msec}$ for RT2. Category correspondence interacted with SOA in such a way that the correspondence effects were larger at the 0- and 100-msec SOAs than at the 300- and 900msec SOAs. Logan and Schulkind demonstrated similar results when T1 and T2 involved digit magnitude (Experiment 2), digit parity (Experiment 2), and word/nonword (Experiments 3 and 4) judgments. The correspondence effects on RT1 in these experiments imply that even highlevel semantic relations for $\mathrm{T} 2$ can be activated prior to response selection for $\mathrm{T} 1$.

In addition to the sessions in which the same categorization task was performed for $\mathrm{T} 1$ and $\mathrm{T} 2$, Logan and Schulkind's (2000) Experiment 2 included sessions in which different tasks were performed on digit stimuli: In one session, magnitude judgments were made for $\mathrm{T} 1$ and parity judgments for $\mathrm{T} 2$; in another session, parity judgments were made for $\mathrm{T} 1$ and magnitude judgments for $\mathrm{T} 2$. For these sessions, no category correspondence effect was evident for either RT1 or RT2. Lien, Schweickert, and Proctor (2002) obtained similar results in their Experiment 3 in which $\mathrm{T} 1$ required classifying a digit as either odd or even and $\mathrm{T} 2$ required classifying a letter as either a consonant or a vowel, or vice versa. When subjects knew which specific task would be performed for $\mathrm{T} 1$ and which for $\mathrm{T} 2$, there was no cross-task correspondence effect. The absence of effects in Lien, Schweickert, and Proctor's Experiment 3 when $\mathrm{T} 1$ and $\mathrm{T} 2$ were different and known in advance implies that the correspondence effects were not due to R1-R2 associations. This is because, with keypress responses for $\mathrm{T} 1$ and $\mathrm{T} 2$, the same response relations were present regardless of whether T1 and T2 were the same or different. By implication, the correspondence effects seem to reflect $\mathrm{S}-\mathrm{R}$ associations, by way of which the stimulus for one task produces activation of the response for the other task.

In Lien, Schweikert, and Proctor's (2002) Experiments 1 and 2, the two tasks could be the same or different, as in their Experiment 3, but they were not presented in distinct blocks for which subjects knew which task would be T1 and which T2. In Experiment 1, there was complete uncertainty in that either the odd-even or consonant-vowel task could occur as T1 or T2, in any combination. In Experiment 2, all of the trials in a block used the same task for T1 and T2 on each trial or on different tasks. However, which specific task would occur for T1 and T2 in the same-task block, or which for $\mathrm{T} 1$ and which for $\mathrm{T} 2$ in the different-task block, was unknown. Strong cross-task correspondence effects were observed for RT1 and RT2 in both experiments, with the effects being larger when T1 and $\mathrm{T} 2$ were the same than when they were different. Thus, simply having two different tasks is insufficient to eliminate the cross-task correspondence effects. Activation of the response for the wrong task seems to occur to 
some extent when the tasks are different, as long as the possibility exists of having to perform either task for T1 or T2.

The studies described in this section indicate that correspondence effects between the two tasks occur when the $\mathrm{S}-\mathrm{R}$ sets for the tasks have conceptual similarity. Results from Greenwald's (1972) study, described earlier, show that these cross-talk effects tend to be reduced when the modalities of the stimuli for each task are highly compatible with the modalities of their respective responses. The low ideomotor compatibility condition of his experiment, in which vocal responses "left" and "right" were made to left and right arrows and manual responses left and right to the spoken words "left" and "right," showed substantial correspondence effects so that RT was much slower when the location information for the two tasks was in conflict than when it was not $(139 \mathrm{msec}$ for the vocal responses and $118 \mathrm{msec}$ for the manual responses). However, the high ideomotor compatibility condition, in which the vocal responses were made to the spoken words and the manual responses to the visual arrows, showed no significant correspondence effects $(10 \mathrm{msec}$ for the vocal responses and $11 \mathrm{msec}$ for the manual responses). When $\mathrm{S}-\mathrm{R}$ translation involves spatial information for one task and linguistic information for the other, as in Greenwald's (1972) high ideomotor compatibility condition, the strength of $\mathrm{S}-\mathrm{R}$ association within each task is strong and the cross-talk between T1 and T2 will be minimal. However, when S-R translation involves spatial or linguistic information for both tasks, the strength of $\mathrm{S}-\mathrm{R}$ association between tasks will be stronger and cross-talk between $\mathrm{T} 1$ and $\mathrm{T} 2$ will have a significant impact on RT1 and RT2.

In sum, the cross-talk effects found in the PRP paradigm suggest that there are substantial correspondence effects from different sources of stimulus and response attributes. These results are consistent with the view that the responseselection stage incorporates two components, response activation and response selection. Translation of S2 into response activation occurs in parallel with the processing of T1, but response selection itself for T2 does not occur until that for T1 is completed.

\section{Do Element-Level Mapping Effects Interact with SOA?}

The influence of element-level mapping manipulations for T2 on the PRP effect are particularly diagnostic regarding whether a bottleneck exists for the response-selection stage because their effects are presumed to be entirely on that stage. One of the most widely cited studies in which $\mathrm{T} 2$ response-selection variables had an additive effect with SOA, consistent with the RSB model, is that of McCann and Johnston (1992). They manipulated S-R mapping rules, either consistent or arbitrary, in order to alter the response-selection processing for T2, with SOAs of 50, 150, 300, and $800 \mathrm{msec}$. In Experiment 1, T1 required a "high" or "low" vocal response to a tone, and T2 involved mapping six stimuli onto six responses: Three sizes of triangles and three sizes of circles were mapped onto the index, middle, and ring fingers of each hand, with one stimulus type mapped consistently and the other arbitrarily. For the consistent mapping, the sizes of stimuli corresponded to the positions of the responding fingers. For the arbitrary mapping, the sizes of stimuli were randomly mapped to the positions of the responding fingers. As predicted by the RSB model, the effect of mapping did not interact significantly with that of SOA.

Although not significant, the mapping effect in McCann and Johnston's (1992) Experiment 1 tended toward an underadditive interaction with SOA, being 72 and $55 \mathrm{msec}$ at the 800- and 50-msec SOAs. Van Selst et al. (1999) found a similar tendency toward underadditivity with their manipulation of ordered versus arbitrary mapping of eight T2 stimuli (four numerals and four letters) to four response keys. This interaction was nonsignificant in Sessions 1-3 (mapping effects of 232 and $180 \mathrm{msec}$ at the longest and shortest SOAs, respectively) but significant in Sessions 27-36 (mappings effects of 25 and $12.5 \mathrm{msec}$ at the longest and shortest SOAs, respectively). The interaction also was significant in Ruthruff, Johnston, and Van Selst's (2001) Experiment 1, which followed up Van Selst et al.'s study with the same highly practiced subjects but with a different T1 (mapping effects of 27 and $10 \mathrm{msec}$ at the longest and shortest SOAs, respectively). The tendency toward an underadditive interaction of the SRC effect with SOA in these studies implies that at least part of the process for translating $\mathrm{S} 2$ into a response can occur as $\mathrm{T} 1$ is being performed. All of these studies used vocal responses for T1. The one experiment that used keypresses, Ruthruff, Johnston, and Van Selst's Experiment 3, did not show any sign of underadditivity. However, because their subjects were already highly practiced, it is not clear whether the response modality of T1 (in relation to that for T2) was a critical factor.

McCann and Johnston's (1992) Experiment 2 used the same auditory-vocal task for T1 as in their Experiment 1 but a different visual-keypress task for T2. Two levels of mapping difficulty were used for T2. In the "easy" condition, subjects were to make a right response to a right-pointing arrow or a left response to a left-pointing arrow. In the "difficult" condition, subjects were to respond left or right to the letter $M$ or $T$. Letter and arrow stimuli were randomly intermixed and displayed in left or right locations, with location being irrelevant. Compared with the letter stimuli, the arrow stimuli have natural associations with the concept of left and right and should be more easily translated into left and right response codes. Responses were in fact faster for the arrow task than for the letter task, and this SRC effect was additive with SOA $(59 \mathrm{msec}$ at the shortest SOA and $55 \mathrm{msec}$ at the longest SOA), an outcome consistent with the RSB model. Lien and Proctor (2000) replicated this result in their Experiment 1, with the effect being $89 \mathrm{msec}$ at the shortest SOA and $92 \mathrm{msec}$ at the longest SOA. In both studies, the RT advantage for the arrow stimuli over the letter stimuli did not interact with the SOA manipulation.

Although McCann and Johnston (1992) obtained differences in RT between the easy and difficult mappings in their two experiments, neither of the compatibility vari- 
ables they used can be classified as standard manipulations. In their Experiment 1, subjects had to determine the hand for $\mathrm{R} 2$ on the basis of the shape that was presented and the specific finger to press on the basis of stimulus size, with the mapping of size to fingers being orderly for one hand (small to large sizes mapped left to right) and not for the other. Clearly, this is a complex task in which it is unclear exactly how subjects would go about performing response selection. A similar argument applies to Van Selst et al.'s (1999) and Ruthruff, Johnston, and Van Selst's (2001) compatibility manipulation in which two sets of stimuli were mapped to a single set of responses, one in an ordered manner and one in an arbitrary manner. In McCann and Johnston's Experiment 2, highly compatible arrow stimuli were intermixed with letter stimuli that had no dimensional overlap with the responses. Mixing different compatibility levels of mappings as in Experiment 2, as well as in their Experiment 1, is known to alter response selection systematically, relative to blocks of pure mappings, and typically to reduce the benefit of compatible mappings (e.g., Ehrenstein \& Proctor, 1998).

From the standpoint of the SRC literature, a more appropriate way to evaluate whether T2 compatibility has additive or interactive effects with SOA is to have a direct, compatible mapping of spatial information for one condition and an incompatible mapping of that information for the other. Moreover, the compatible and incompatible mappings should not be mixed within blocks of trials because the compatibility effect is reduced or eliminated when mappings are mixed (Proctor \& Vu, in press). Lien and Proctor (2000) conducted two experiments similar to McCann and Johnston's (1992) Experiment 2 but used only the arrow stimuli for T2 and had half of the subjects perform with a compatible mapping and half with an incompatible mapping of the arrow directions to the responses. In both experiments, left and right keypress responses with a single hand were made to the arrows for T2. T1 was a manual response with the other hand to a high- or lowpitch tone in Experiment 2 and to the centered letter $M$ or $T$ in Experiment 3. Both experiments showed an overadditive interaction of compatibility and SOA, with the mapping effect being much larger at the 50-msec SOA (149 and $348 \mathrm{msec}$ in Experiments 2 and 3, respectively) than at the $800-\mathrm{msec}$ SOA (67 and $223 \mathrm{msec}$, respectively). We obtained a similar, though smaller, overadditive interaction (156 and $126 \mathrm{msec}$ at the 50- and 800-msec SOAs, respectively) in an unpublishedexperiment that was like their Experiment 2, except that the arrows were presented in the center of the screen to prevent possible contributions of eye movements and irrelevant location effects.

Schumacher et al. (1999) manipulated spatial compatibility in their Experiments 3 and 4. T1 was a high-low tone discrimination that required keypress responses in Experiment 3 and vocal "high"-"low" responses in Experiment 4. T2 involved the letter $O$ presented in one of four locations in a horizontal row. Responses were made with the index, middle, ring, and little fingers of the right hand placed on four keys. For compatible mapping blocks, the key corre- sponding to the location of the stimulus was to be pressed. For incompatible mapping blocks, the assignment of keys to stimulus locations was arbitrary. Subjects performed the task for three sessions, the first of which was practice. For Experiment 3, in which manual responses were required for both tasks, the compatibility effect was approximately additive with that of SOA in Session 2, but it was strongly underadditive in Session 3. Schumacher et al. attributed the additive effect in Session 2 to the subjects' adopting a cautious lockout strategy until they became relatively highly practiced, because both tasks required manual responses. Consistent with this hypothesis, in their Experiment 4 , in which responses for $\mathrm{T} 1$ were vocal and those for T2 manual, the compatibility effect showed a strong underadditive interaction with SOA in both sessions.

There are numerous differences between the experimental designs used by Lien and Proctor (2000) and Schumacher et al. (1999) that could explain the discrepancy of interaction patterns obtained. Subjects received more practice in Schumacher et al.'s experiments than in ours, and practice was a factor that Schumacher et al. argued is crucial in regard to strategies that subjects might adopt. The compatibility manipulations in our experiments were between subjects, whereas Schumacher et al. had each subject use both mappings in different blocks of trials. Switching between mappings across blocks could preclude subjects from obtaining the full benefit of the compatible mapping, much as mixing mappings within blocks of trials does. Other differences that could matter are the use of arrows as opposed to locations and two versus four choices. The most likely factor of importance, however, is a difference in the opportunity for cross-talk between T1 and T2 in the two studies. In Schumacher et al.'s Experiment 4 , there was little possibility for cross-talk because T1 required "high"-“low" vocal responses to high-low tone pitches, and $\mathrm{T} 2$ required one of four keypresses to one of four stimulus locations. In their Experiment 3, they used keypresses for the T1 tone-identificationtask, but the fact that there were only two response alternatives likely served to differentiate the $\mathrm{T} 1$ response set sufficiently from the four-choice response set for T2. In other words, the high- and low-pitch tones for $\mathrm{T} 1$ were associated to two relative response locations, and the four stimulus locations for $\mathrm{T} 2$ were associated to four relative response locations. Consequently, there was little tendency for a stimulus for one task to activate a response for the other task. In our experiments, both tasks required two keypress responses, and the stimulus for one task tended to activate the same relative response location for the other task. Consistent with this hypothesis, our Experiment 1, in which the T1 responses were the spoken words "high" or "low," showed an underadditive interaction with SOA of arrow mapping to responses for $\mathrm{T} 2$. This outcome must be taken with caution, though, since letter stimuli were intermixed with the arrow stimuli for $\mathrm{T} 2$.

Two of the studies mentioned above examined effects of irrelevant location on performance (i.e., the Simon effect). In McCann and Johnston's (1992) Experiment 2, the let- 
ters and arrows for $\mathrm{T} 2$ could occur in either a left or right location. The Simon effect, which has been assumed to affect response selection, showed an underadditive interaction of location correspondence with SOA across the letter and arrow stimuli (which were compatibly mapped to responses). In other words, the advantage of responding to $\mathrm{T} 2$ when the $\mathrm{S} 2$ and $\mathrm{R} 2$ locations corresponded than when they did not was eliminated at short SOAs. Lien and Proctor (2000) obtained a similar underadditive pattern of the normal Simon effect and SOA for the compatible arrow mapping, both when letter stimuli were intermixed, as in McCann and Johnston's study, and when they were not. One explanation for this underadditive interaction is that the response corresponding to S2 location was automatically activated when S2 occurred and then decayed. We noted that a dual-route model of the Simon effect proposed by De Jong et al. (1994), which includes automatic activation and decay as one component, would predict that the reverse Simon effect typically obtained when the relevant stimulus dimension is incompatibly mapped to the responses (e.g., Hedge \& Marsh, 1975) should increase as SOA decreases. We obtained a reverse Simon effect when the mapping of $\mathrm{T} 2$ arrow direction to responses was incompatible, but this reverse Simon effect showed an underadditive interaction with SOA, rather than the predictive overadditiveinteraction. The underadditiveinteractions of the Simon effect and the reverse Simon effect can be accommodated by Hommel's (1998) approach, according to which response activation must be distinguished from the response-selection decision.

Fagot and Pashler (1992) conducted an experiment using the Stroop color-naming task for T2 that was similar to the experiments of McCann and Johnston (1992) and Lien and Proctor (2000) that used the Simon task. In Fagot and Pashler's Experiment 7, T1 required a left or right keypress to indicate whether a tone pitch was high or low. For T2, the word RED, GREEN, or BLUE was presented in a congruent or incongruent color, and the color was to be named vocally. RT2 was approximately $100 \mathrm{msec}$ faster when the color word and color corresponded than when they did not, and this effect did not interact with SOA. The exact reason for the deviation of Fagot and Pashler's results from those of McCann and Johnston and of Lien and Proctor (2000) is not clear because the experimental designs differed in several respects. However two points are worth noting. First, Fagot and Pashler's RT2 data show a tendency toward underadditivity that we estimate from their Figure 12 as being $20 \mathrm{msec}$. This value is similar to the 33 and 23-msec underadditivity reported in McCann and Johnston's Experiment 2 and in Lien and Proctor's Experiment 1, which used different response modalities for T1 and T2 (vocal R1 and manual R2). Second, Fagot and Pashler's longest SOA was 450 msec, compared with 800 msec in the other two studies. The Simon effect in those studies was larger at the 800-msec SOA than at the 300msec SOA, which was closest to the longest SOA in Fagot and Pashler's study. Consequently, the use of $450 \mathrm{msec}$ as the longest SOA in Fagot and Pashler's experiment may have resulted in underestimation of the underadditive interaction.

\section{Other Response-Selection Variables}

Other variables in addition to SRC that have been manipulated for T2 in the PRP paradigm to affect responseselection difficulty are the number of $S-R$ alternatives and repetition/nonrepetition of the $S-R$ pair. As mentioned previously, the studies of Van Selst and Jolicœur (1997) and Schubert (1999) reported additive effects of number of $\mathrm{S}-\mathrm{R}$ pairs and SOA, whereas Schumacher et al. (1999) found an underadditive interaction. In the first two studies, the number of $\mathrm{S}-\mathrm{R}$ pairs was two or three, with each stimulus being assigned a unique response. The increase in the number of $\mathrm{S}-\mathrm{R}$ pairs likely influenced, primarily, the final response-decision difficulty, which would have led to the observed additive effects with SOA. In contrast, Schumacher et al. varied whether one or two stimuli were mapped to each of two responses, with the mapping being a high-/low-pitch discrimination for the easy task (1120-Hz vs. $1650-\mathrm{Hz}$ tones) and an intermediate versus extreme discrimination for the difficult task (one response to $500-$ or $1120-\mathrm{Hz}$ tones and another response to 330- or $1650-\mathrm{Hz}$ tones). With this manipulation, the responseselection decision is two-choice in both cases, suggesting that the final response-selection difficulty is similar. What differs is the nature of the information on which the decision must be based, being high- or low-pitch discrimination for the two-stimulus version and intermediate or extreme pitch for the four-stimulus version. This difference in discrimination difficulty would likely affect the time to classify the stimulus and translate it into the assigned response, leading to the resulting underadditive interaction.

Another finding mentioned previously was that Pashler and Johnston (1989) found the advantage of immediate repetition of the $\mathrm{S}-\mathrm{R}$ pair for $\mathrm{T} 2$ from the previous trial to be additive with SOA. In terms of Hommel's (1998) twoprocess approach, the additive effects suggest that the repetition variable has its influence on the final response selection and not on response activation. It is typical to attribute repetition benefits to automatic activation or intentional expectancy (Soetens, 1998). The former is assumed to contribute primarily at short response-stimulus intervals of less than $500 \mathrm{msec}$ and the latter at longer intervals. In Pashler and Johnston's (1989) experiment, the intertrial interval was $1.8 \mathrm{sec}$, plus a 2 -sec message on error trials. The SOA was varied from 50 to $400 \mathrm{msec}$, and $\mathrm{T} 1$ intervened between the successive occurrences of T2. Given this situation, it is clear that the repetition effect would not have had its basis in automatic activation but in intentional expectancies. Therefore, it is reasonable to assume that these expectancies have their primary influence on final response selection and not on response activation.

\section{Summary}

Greenwald and Shulman (1973) reported that the PRP effect could be eliminated when two tasks are ideomotor compatible. However, Lien, Proctor, and Allen's (2002) 
replication of their study and Brebner's (1977) experiment, in which two ideomotor compatible tasks were used, obtained a PRP effect. The primary finding from these studies was that the PRP effect was reduced but not eliminated for two ideomotor compatible tasks in which the dimensional overlap of the stimulus and response sets across the tasks was low. Several researchers have tried to eliminate the PRP effect by giving subjects extended practice. Again, the typical finding is that the PRP effect is reduced in magnitude but not eliminated.

Duncan (1979) demonstrated that response selection for $\mathrm{T} 1$ is affected by the $\mathrm{S}-\mathrm{R}$ mapping that is in effect for $\mathrm{T} 2$, and vice versa. When there is dimensional overlap between the two tasks, there will be cross-talk between the stimuli and responses for the respective tasks (Hommel, 1998). This cross-talk has a larger impact on performance at short SOAs, when the temporal overlap between the two tasks is great, than at long SOAs. That the cross-talk effects are evident for $\mathrm{T} 1$, as well as for $\mathrm{T} 2$, implies that some processing pertaining to response selection for $\mathrm{T} 2$ occurs while $\mathrm{T} 1$ is being performed.

Models of the PRP effect tend to consider response selection as a single processing component that is responsible for all mapping effects and set size effects. On the basis of this assumption, the RSB model predicts additive effects of S2-R2 mapping variables and SOA on T2 performance. Although a few studies have reported functions that did not deviate significantly from additivity, the designs of these studies were not optimal for evaluating compatibility effects. Those studies that have used more standard compatibility manipulations, with mappings being varied between subjects or blocks of trials, have reported both overadditive (Lien \& Proctor, 2000) and underadditive (Schumacher et al., 1999) interactions. In the SRC literature, response selection tends to be treated as having two distinct processing components-automatic activation and intentional selection-whose contributions to performance vary as a function of the type of mapping manipulation. In fact, in Kornblum et al.'s (1990) influential model, intentional selection is required on all trials, regardless of whether automatic response activation occurs. Once it is accepted that response selection is not unitary and that both response-selection components might vary as a function of the nature of the task and mapping manipulation, it is not surprising that various interaction patterns are observed when compatibility and SOA are manipulated in the PRP paradigm.

\section{CONCLUSION}

Although SRC and PRP effects are typically attributed to response-selection processes, they have been studied relatively independently. The considerable literature on SRC effects is minimally informed by the vast literature on PRP effects, and vice versa. The premise of this paper was that a more complete understanding of response-selection mechanisms emerges from joint consideration of the two literatures and studies of compatibility effects in the PRP paradigm. We reviewed, evaluated, and considered the findings for SRC effects, PRP effects, and the influence of SRC on the PRP effect.

One implication of the SRC research is that response selection involves at least two distinct routes, automatic activation and intentional translation. Automatic activation is presumed to arise from long-term $\mathrm{S}-\mathrm{R}$ associations such as those between corresponding spatial locations, whereas intentional translation is based on short-term associations specific to the assigned task. A second implication from the SRC research, entailed by the concept of automatic activation, is that irrelevant stimulus attributes might activate their corresponding responses, with the strength of this activation being a function of conceptual and perceptual similarity among the relevant stimulus dimension, irrelevant stimulus dimension, and the response dimension. A third implication is that the response activation produced by an irrelevant stimulus dimension will decrease after the point in time at which it attains its maximal value.

Most models of the PRP effect, including the widely accepted RSB model, treat response selection as a stage within a single processing route, with that for $\mathrm{T} 1$ and $\mathrm{T} 2 \mathrm{oc}-$ curring in two separate streams. The differences in the models involve the time courses of the component processes, with the issues revolving around whether response selection for the two tasks can be performed concurrently. The view of response selection emerging from the research on SRC effects suggests that response selection is more complex and less under the subject's control than is implied by the PRP literature. The numerous studies of the PRP effect conducted over the past 50 years show that in a wide variety of situations that differ in terms of the specific tasks that must be performed and the stimulus and response modalities, two responses cannot be selected concurrently without interference.

The studies of the influence of SRC on the PRP effect indicate more specifically that the interference is not eliminated even when the two tasks are highly compatible. Although the statement is often made that the PRP effect is eliminated when two tasks are ideomotor compatible, the evidence does not support this statement. With the exception of the finding of Greenwald and Shulman's (1973) Experiment 2, which has not been replicated in any similar experiment, a PRP effect has been obtained when both tasks were ideomotor compatible. Although the magnitude of the PRP effect is reduced with practice, extended practice does not eliminate the effect entirely. An implication of these findings is that response-selection decisions are always required for tasks, even when they involve highly compatible or overlearned S-R mappings. Moreover, because the RSB model characterizes response selection as a single intentional act performed separately for each task, it implies that there should be little cross-talk between tasks. However, as would be expected on the basis of single-task SRC effects, PRP studies in which 
there is similarity between $\mathrm{T} 1$ and $\mathrm{T} 2$ show both forward and backward correspondence effects between the two tasks. These correspondence effects typically are strongest at short SOAs, as would be expected if the activation produced by a stimulus occurs automatically and then decays if the activation is irrelevant. The implication of these cross-task correspondence effects is that compatibility relations between $\mathrm{T} 1$ and $\mathrm{T} 2$, as well as those within the respective tasks, are crucial to dual-task performance.

Hommel (1998) interpreted the cross-task correspondence effects in his study as suggesting that $\mathrm{S}-\mathrm{R}$ translation can be performed automatically and in parallel for two tasks. His general point is that the intention to respond creates links between stimuli and their assigned responses through which automatic activation occurs. In other words, the automatic activation occurs not only by way of longterm $\mathrm{S}-\mathrm{R}$ associations, but also by way of the short-term associations defined for the task. The view that automatic activation can occur on the basis of task-defined associations has not received much attention in the SRC literature and is counter to Kornblum et al.'s (1990) DOM. However, within the SRC literature, recent findings regarding effects of transfer from one mapping to another and of mixing $\mathrm{S}-\mathrm{R}$ mappings within a trial block support this view. Thus, it may serve to resolve issues regarding response selection in single tasks. For example, because Kornblum et al.'s (1990) model does not allow for automatic activation based on task-defined associations, the correspondence effects produced by flanker stimuli that have no dimensional overlap with the targets must be attributed to stimulus identification (Kornblum \& Lee, 1995). The assumption that automatic activation can occur through taskdefined associations enables the flanker effect to be attributed to response activation, consistent with most findings.

The distinction that Hommel (1998) makes between automatic response activation and intentional response selection based on that activation also has important implications. His account implies that only the final response selection involves a bottleneck, either structural or strategic. Thus, any variable that has its effect on this stage should have an additive effect with that of SOA. In contrast, any variable that has its effect on the prebottleneck stage of response activation should have an underadditive interaction with SOA. On the basis of this approach, automatic response activation, by its nature, will occur across tasks when there is similarity along any dimension for the two tasks, regardless of whether the $S-R$ relation involves long-term or short-term task-defined associations. In other words, this activation is not subject to the bottleneck and can occur simultaneously for both tasks.

In the research on single-task performance, it has been typical to assume that a response can be triggered automatically without requiring an intentional selection. Hommel's (1998) account suggests, to the contrary, that a decision based on the activation is always required. The necessity for an intentional response decision is supported by the finding of a residual PRP effect for tasks that are ideomotor compatible or highly practiced. These results suggest that response selection cannot be bypassed, even when $\mathrm{S}-\mathrm{R}$ translation is highly automatized. Interestingly, Kornblum et al.'s (1990) DOM model is the only one of which we are aware that does not allow a response to be initiated on the basis of automatic activation. In their model, the automatically activated response is verified by comparing it with the response identified by way of the intentional route. If the verification is positive, the automatically activated response is executed. The major deviation with respect to intentional identification of Kornblum et al.'s (1990) model for SRC effects from Hommel's (1998) two-process account of dual-task performance is that intentional response selection is not based on automatic response activation in the former but in the latter.

The distinction between response activation and final response selection provides a good start for unifying the study of response selection. However, fundamental questions remain, including how response activation and final response selection are affected by the complex activation produced by multiple stimuli and whether other aspects of response selection need to be distinguished as well. Many of these questions can be answered by systematic investigation of compatibility effects in tasks requiring multiple responses. Researchers primarily interested in compatibility effects should be more concerned with examining performance in such task environments. Researchers interested in the PRP effect should be concerned with controlling and examining relations between tasks, as well as within tasks, choosing response-selection variables systematically on the basis of their likely effects on information processing.

\section{REFERENCES}

Allport, D. A., Antonis, B., \& Reynolds, P. (1972). On the division of attention: A disproof of the single-channel hypothesis. Quarterly Journal of Experimental Psychology, 24, 225-235.

Baldo, J. V., Shimamura, A. P., \& Prinzmetal, W. (1998). Mapping symbols to response modalities: Interference effects on Stroop-like tasks. Perception \& Psychophysics, 60, 427-437.

Brebner, J. (1977). The search for exceptions to the psychological refractory period. In S. Dornic (Ed.), Attention and performance VI (pp. 63-78). Hillsdale, NJ: Erlbaum.

Broadbent, D. E. (1958). Perception and communications. Oxford: Pergamon.

BroAdBEnT, D. E. (1982). Task combination and the selective intake of information. Acta Psychologica, 50, 253-290.

Coles, M. G. H., Gratton, G., Bashore, T. R., Eriksen, C. W., \& Donchin, E. (1985). A psychophysiological investigation of the continuous flow model of human information processing. Journal of Experimental Psychology: Human Perception \& Performance, 11, 529-553.

CRAfT, J. L., \& Simon, J. R. (1970). Processing symbolic information from a visual display: Interference from an irrelevant directional cue. Journal of Experimental Psychology, 83, 415-420.

DAvis, R. (1957). The human operator as a single channel information system. Quarterly Journal of Experimental Psychology, 9, 119-129.

DAVIS, R. (1959). The role of "attention" in the psychological refractory period. Quarterly Journal of Experimental Psychology, 11, 211-220.

DE Jong, R. (1993). Multiple bottlenecks in overlapping task performance. Journal of Experimental Psychology: Human Perception \& Performance, 19, 965-980. 
DE Jong, R. (1995). Perception-action coupling and S-R compatibility. Acta Psychologica, 90, 287-299.

De Jong, R., Liang, C.-C., \& Lauber, E. (1994). Conditional and unconditional automaticity: A dual-process model of effects of spatial stimulus-response correspondence. Journal of Experimental Psychology: Human Perception \& Performance, 20, 731-750.

DuncAn, J. (1977a). Response selection errors in spatial choice reaction tasks. Quarterly Journal of Experimental Psychology, 29, 415-423.

Duncan, J. (1977b). Response selection rules in spatial choice reaction tasks. In S. Dornic (Ed.), Attention and performance VI (pp. 49-61). Hillside, NJ: Erlbaum.

Duncan, J. (1979). Divided attention: The whole is more than the sum of its parts. Journal of Experimental Psychology: Human Perception \& Performance, 5, 216-228.

Dutta, A., \& Proctor, R. W. (1992). Persistence of stimulus-response compatibility effects with extended practice. Journal of Experimental Psychology: Learning, Memory, \& Cognition, 18, 801-809.

Ehrenstein, A., \& Proctor, R. W. (1998). Selecting mapping rules and responses in mixed four-choice tasks. Psychological Research, 61, 231-248.

EriKsen, B. A., \& ERIKSEN, C. W. (1974). Effects of noise letters upon the identification of a target letter in a nonsearch task. Perception \& Psychophysics, 16, 143-149.

Eriksen, C. W., \& Hoffman, J. E. (1972). Some characteristics of selective attention in visual perception determined by vocal reaction time. Perception \& Psychophysics, 11, 169-171.

Fagot, C., \& PAShler, H. (1992). Making two responses to a single object: Implications for the central attentional bottleneck. Journal of Experimental Psychology: Human Perception \& Performance, 18, 1058 1079.

Fitts, P. M., \& Deininger, R. L. (1954). S-R compatibility: Correspondence among paired elements within stimulus and response codes. Journal of Experimental Psychology, 48, 483-492.

Fitts, P. M., \& SEeger, C. M. (1953). S-R compatibility: Spatial characteristics of stimulus and response codes. Journal of Experimental Psychology, 46, 199-210.

Fletcher, B. C., \& Rabbitt, P. M. A. (1978). The changing pattern of perceptual analytic strategies and response selection with practice in a two-choice reaction time task. Quarterly Journal of Experimental Psychology, 30, 417-427.

GoTTSDANKER, R. (1979). A psychological refractory period or an unprepared period? Journal of Experimental Psychology: Human Perception \& Performance, 5, 208-215.

Gottsdanker, R, \& Stelmach, G. E (1971). The persistence of psychological refractoriness. Journal of Motor Behavior, 3, 301-312.

GreenWALD, A. G. (1970a). A choice reaction time test of ideomotor theory. Journal of Experimental Psychology, 86, 20-25.

Greenwald, A. G. (1970b). Sensory feedback mechanism in performance control: With special reference to the ideo-motor mechanism. Psychological Review, 77, 73-99.

Greenwald, A. G. (1972). On doing two things at once: Time-sharing as a function of ideomotor compatibility. Journal of Experimental Psychology, 94, 52-57.

Greenwald, A. G., \& Shulman, H. G. (1973). On doing two things at once: II. Elimination of the psychological refractory period effect. Journal of Experimental Psychology, 101, 70-76.

HasbroucQ, T., \& Guiard, Y. (1991). Stimulus-response compatibility and the Simon effect: Toward a conceptual clarification. Journal of Experimental Psychology: Human Perception \& Performance, 17, 246-266.

Hedge, A., \& Marsh, N. W. A. (1975). The effects of irrelevant spatial correspondences on two-choice response time. Acta Psychologica, 39, 427-439.

Hommel, B. (1993a). Inverting the Simon effect by intention: Determinants of direction and extent of effects of irrelevant spatial information. Psychological Research, 55, 270-279.

Hommel, B. (1993b). The relationship between stimulus processing and response selection in the Simon task: Evidence for a temporal overlap. Psychological Research, 55, 280-290.

Hommel, B. (1994). Spontaneous decay of response code activation. Psychological Research, 56, 261-268.

Hommel, B. (1996). S-R compatibility effects without response uncertainty. Quarterly Journal of Experimental Psychology, 49A, 546-571.
Hommel, B. (1997). Toward an action-concept model of stimulusresponse compatibility. In B. Hommel \& W. Prinz (Eds.), Theoretical issues in stimulus-response compatibility (pp. 281-320). Amsterdam: North-Holland.

Hommel, B. (1998). Automatic stimulus-response translation in dualtask performance. Journal of Experimental Psychology: Human Perception \& Performance, 24, 1368-1384.

Ivry, R. B., Franz, E. A., Kingstone, A., \& Johnston, J. C. (1998). The psychological refractory period effect following callosotomy: Uncoupling of lateralized response codes. Journal of Experimental Psychology: Human Perception \& Performance, 24, 463-480.

Kahneman, D. (1973). Attention and effort. EnglewoodCliffs, NJ: Prentice Hall.

Kantowitz, B. H., \& Knight, J. L. (1976). Testing tapping timesharing. II. Auditory secondary task. Acta Psychologica, 40, 343-362.

Karlin, L., \& Kestenbaum, R. (1968). Effects of number of alternatives on the psychological refractory period. Quarterly Journal of Experimental Psychology, 20, 167-178.

Keele, S. W. (1973). Attention and human performance. Pacific Palisades, CA: Goodyear.

Keele, S. W. (1986). Motor control. In K. R. Boff, L. Kaufman, \& J. P. Thomas (Eds.), Handbook of perception and human performance (Vol. 2, pp. 30-1 to 30-60). New York: Wiley.

Kinsbourne, M., \& Hicks, R. F. (1978). Functional cerebral space: A model for overflow, transfer and interference effects in human performance. In J. Requin (Ed.), Attention and performance VII (pp. 345362). Hillsdale, NJ: Erlbaum.

Klapp, S. T., Porter-Graham, K. A., \& Hoifjeld, A. R. (1991). The relation of perception and motor action: Ideomotor compatibility and interference in divided attention. Journal of Motor Behavior, 23, 155-162.

Kornblum, S. (1992). Dimensional overlap and dimensional relevance in stimulus-response and stimulus-stimulus compatibility. In G. E. Stelmach \& J. Requin (Eds.), Tutorials in motor behavior II (pp. 743777). Amsterdam: North-Holland.

Konnblum, S. (1994). The way irrelevant dimensions are processed depends on what they overlap with: The case of Stroop-and Simon-like stimuli. Psychological Research, 56, 130-135.

Kornblum, S., Hasbroucq, T., \& Osman, A. (1990). Dimensional overlap: Cognitive basis for stimulus-response compatibility-A model and taxonomy. Psychological Review, 97, 253-270.

Kornblum,S., \& LeE, J.-W. (1995). Stimulus-response compatibility with relevant and irrelevant stimulus dimensions that do and do not overlap with the response. Journal of Experimental Psychology: Human Perception \& Performance, 21, 855-875.

Kornblum, S., Stevens, G. T, Whipple, A., \& Requin, J. (1999). The effects of irrelevant stimuli: 1 . The timecourse of stimulus-stimulus and stimulus-response consistency effects with Stroop-like stimuli, Simonlike tasks, and their combinations. Journal of Experimental Psychology: Human Perception \& Performance, 25, 688-714.

LeVy, J., \& PAshler, H. (2001). Is dual-task slowing instruction dependent? Journal of Experimental Psychology: Human Perception \& Performance, 27, 862-869.

Lien, M.-C., \& Proctor, R. W. (2000). Multiple spatial correspondence effects on dual-task performance. Journal of Experimental Psychology: Human Perception \& Performance, 26, 1260-1280.

Lien, M.-C., Proctor, R. W., \& Allen, P. A. (2002). Ideomotor compatibility in the psychological refractory period effect: 29 years of oversimplification. Journal of Experimental Psychology: Human Perception \& Performance, 28, 396-409.

Lien, M.-C., Schweickert, R. \& Proctor, R. W. (2002). Task switching and response correspondence in the psychological refractory period paradigm. Manuscript submitted for publication.

Logan, G. D., \& Schulkind, M. D. (2000). Parallel memory retrieval in dual-task situations: I. Semantic memory. Journal of Experimental Psychology: Human Perception \& Performance, 26, 1260-1280.

Lu, C. -H., \& Proctor, R. W. (1994). Processing of an irrelevant location dimension as a function of the relevant stimulus dimension. Journal of Experimental Psychology: Human Perception \& Performance, 20, 286-298.

Lu, C. -H., \& Proctor, R. W. (1995). The influence of irrelevant location information on performance: A review of the Simon and spatial Stroop effects. Psychonomic Bulletin \& Review, 2, 174-207. 
Lu, C. -H., \& Proctor, R. W. (2001). Influence of irrelevant information on human performance: Effects of S-R association strength and relative timing. Quarterly Journal of Experimental Psychology, 54A, 95-136.

MACLEOD, C. M. (1991). Half a century of research on the Stroop effect: An integrative review. Psychological Bulletin, 109, 163-203.

Marble, J. G., \& Proctor, R. W. (2000). Mixing location-relevant and location-irrelevant choice-reaction tasks: Influences of location mapping on the Simon effect. Journal of Experimental Psychology: Human Perception \& Performance, 26, 1515-1533.

McCann, R. S., \& Johnston, J. C. (1992). Locus of the single-channel bottleneck in dual-task interference. Journal of Experimental Psychology: Human Perception \& Performance, 18, 471-484.

McLeod, P. (1977). A dual task response modality effect: Support for multiprocessor models of attention. Quarterly Journal of Experimental Psychology, 29, 651-667.

McLeod, P., \& Posner, M. I. (1984). Privileged loops from percept to act. In H. Bouma \& D. G. Bouwhuis (Eds.), Attention and performance X: Control of language processes (pp. 55-66). Hillsdale, NJ: Erlbaum.

Meyer, D. E., \& Kieras, D. E. (1997a). A computational theory of executive cognitive processes and multiple-task performance: Part 1. Basic mechanisms. Psychological Review, 104, 3-65.

Meyer, D. E., \& Kieras, D. E. (1997b). A computational theory of executive cognitive processes and multiple-task performance: Part 2. Accounts of psychological refractory-period phenomena. Psychological Review, 104, 749-791.

Miller, J. (1982). Divided attention: Evidence for coactivation with redundant signals. Cognitive Psychology, 14, 247-279.

Miller, J. (1987). Evidence of preliminary response preparation from a divided attention task. Journal of Experimental Psychology: Human Perception \& Performance, 13, 425-434.

MiLLER, J. (1991). The flanker compatibility effect as a function of visual angle, attention focus, visual transients, and perceptual load: A search for boundary conditions. Perception \& Psychophysics, 49, 270-288.

Moray, N. (1967). Where is capacity limited? A survey and a model. Acta Psychologica, 27, 84-92.

MorILL, T. (1957). The psychological refractory phase. British Journal of Psychology, 48, 93-97.

Mowbray, G. H., \& RHoAdes, M. V. (1959). On the reduction of choice reaction times with practice. Quarterly Journal of Experimental Psychology, 14, 1-36.

Navon, D., \& Miller, J. (1987). Role of outcome conflict in dual-task interference. Journal of Experimental Psychology: Human Perception \& Performance, 13, 435-448.

O'Leary, M. J., \& Barber, P. J. (1993). Interference effects in the Stroop and Simon paradigm. Journal of Experimental Psychology: Human Perception \& Performance, 19, 830-844.

PAshler, H. (1984). Processing stages in overlapping tasks: Evidence for a central bottleneck. Journal of Experimental Psychology: Human Perception \& Performance, 10, 358-377.

PAshler, H. (1989). Dissociations and dependencies between speed and accuracy: Evidence for a two-component theory of divided attention in simple tasks. Cognitive Psychology, 21, 469-514.

PAshler, H. (1990). Do response modality effects support multiprocessor models of divided attention? Journal of Experimental Psychology: Human Perception \& Performance, 16, 826-842.

Pashler, H. (1993). Doing two things at the same time. American Scientist, 81, 48-55.

PASHLER, H. (1994). Dual-task interference in simple tasks: Data and theory. Psychological Bulletin, 16, 220-224.

PASHLER, H. (1997). The psychology of attention. Cambridge, MA: MIT Press.

Pashler, H. (1998). Attention. Hove, U.K.: Psychology Press.

PASHLER, H. (2000). Task switching and multitask performance. In S. Monsell \& J. Driver (Eds.), Attention and performance XVIII: Control of cognitive processes (pp. 277-307). Cambridge, MA: MIT Press.

PASHLER, H., \& BAY Lis, G. (1991). Procedural learning: 1. Locus of practice effects in speeded choice tasks. Journal of Experimental Psychology: Learning, Memory, \& Cognition, 17, 20-32.

Pashler, H., Carrier, M., \& Hoffman, J. (1993). Saccadic eye movements and dual-task interference. Quarterly Journal of Experimental Psychology, 46A, 51-82.
Pashler, H., \& Johnston, J. C. (1989). Chronometric evidence for central postponement in temporally overlapping tasks. Quarterly Journal of Experimental Psychology, 41, 19-45.

PAshler, H., \& Johnston, J. C. (1998). Attentional limitations in dualtask performance. In H. Pashler (Ed.), Attention (pp. 155-189). Hove, U.K.: Psychology Press.

PoSNER, M. I. (1966). Components of skilled performance. Science, 152, 1712-1718.

Proctor, R. W., \& DutTa, A. (1993). Do the same stimulus-response relations influence choice reactions initially and after practice? Journal of Experimental Psychology: Learning, Memory, \& Cognition, 19, 922-930.

Proctor, R. W., \& Lu, C. -H. (1999). Processing irrelevant information: Practice and transfer effects in choice-reaction tasks. Memory \& Cognition, 27, 63-77.

Proctor, R. W., \& Pick, D. F. (1998). Lateralized warning tones produce typical irrelevant-location effects on choice reactions. Psychonomic Bulletin \& Review, 5, 124-129.

Proctor, R. W., \& VU, K. (in press). Eliminating, magnifying, and reversing spatial compatibility effects with mixed location-relevant and irrelevant trials. Attention and performance XIX: Common mechanisms in perception and action. Oxford: Oxford University Press.

Proctor, R. W., \& WANG, H. (1997). Differentiating types of set-level compatibility. In B. Hommel \& W. Prinz (Eds.), Theoretical issues in stimulus-response compatibility (pp. 11-37). Amsterdam: NorthHolland.

Riggio, L., Gawryszewski, L. G., \& Umiltà, C. (1986). What is crossed in crossed-hand effects? Acta Psychologica, 62, 89-100.

Rosenbloom, P. S., \& Newell, A. (1987). An integrated computational model of stimulus-response compatibility and practice. In G. H. Bower (Ed.), The psychologyoflearning and motivation: Advances in research and theory (Vol. 21, pp. 1-52). San Diego: Academic Press.

Roswarski, T. E., \& Proctor, R. W. (1996). Multiple spatial codes and temporal overlap in choice-reaction tasks. Psychological Research, 59, 196-211.

Roswarski, T. E. \& Proctor, R. W. (2000). Auditory stimulus-response compatibility: Is there a contribution of stimulus-hand correspondence? Psychological Research, 63, 148-158.

Ruthruff, E., Johnston, J. C., \& VAn Selst, M. (2001). Why practice reduces dual-task interference. Journal of Experimental Psychology: Human Perception \& Performance, 27, 3-21.

Ruthruff, E., Pashler, H. E., \& KlaAssen, A. (2001). Processing bottlenecks in dual-task performance: Structural limitations or strategic postponement? Psychonomic Bulletin \& Review, 8, 73-80.

SCHubERT, T. (1999). Processing differences between simple and choice reactions affect bottleneck localization in overlapping tasks. Journal of Experimental Psychology: Human Perception \& Performance, 25, 408-425.

Schumacher, E. H., Lauber, E. J., Glass, J. M., Zurbriggen, E. L., Gmeindl, L., Kieras, D. E., \& Meyer, D. E. (1999). Concurrent response-selection processes in dual-task performance: Evidence for adaptive executive control for task scheduling. Journal of Experimental Psychology: Human Perception \& Performance, 25, 791-814.

SCHWEICKERT, R. (1980). Critical-path scheduling of mental processes in a dual task. Science, 209, 704-706.

Schweickert, R., \& Boggs, G. J. (1984). Models of central capacity and concurrency. Journal of Mathematical Psychology, 28, 223-281.

ShafFER, L. H. (1965). Choice reaction with variable S-R mapping. Journal of Experimental Psychology, 70, 284-288.

Simon, J. R. (1969). Reactions toward the source of stimulation. Journal of Experimental Psychology, 81, 174-176.

Simon, J. R. (1990). The effects of an irrelevant directional cue on human information processing. In R. W. Proctor \& T. G. Reeve (Eds.), Stimulus-response compatibility: An integrated perspective (pp. 3186). Amsterdam: North-Holland.

SimON, J. R., \& AcostA, E., JR. (1982). Effect of irrelevant information on the processing of relevant information: Facilitation and/or interference? The influence of experimental design. Perception \& Psychophysics, 31, 383-388.

Simon, J. R., Hinrichs, J. V., \& Craft, J. L. (1970). Auditory S-R compatibility: Reaction time as a function of ear-hand correspondence 
and ear-response-location correspondence. Journal of Experimental Psychology, 86, 97-102.

Simon, J. R., Sly, P. E., \& VilapakKam, S. (1981). Effect of compatibility of S-R mapping on reactions toward the stimulus source. Acta Psychologica, 47, 63-81.

Smith, M. C. (1967a). Stimulus-response compatibility and parallel response selection. Canadian Journal of Psychology, 21, 496-503.

Sмiтh, M. C. (1967b). Theories of the psychological refractory period. Psychological Bulletin, 67, 202-213.

SoEtens, E. (1998). Localizing sequential effects in serial choice reaction time with the information reduction procedure. Journal of Experimental Psychology: Human Perception \& Performance, 24, 547-568.

STERnBERG, S. (1969). The discovery of processing stages: Extensions of Donders' method. Acta Psychologica, 30, 276-315.

STOFFELS, E. -J. (1996). Uncertainty and processing routes in the selection of a response: An S-R compatibility study. Acta Psychologica, 94, 227-252.

Stroop, J. R. (1992). Studies of interference in serial verbal reactions. Journal of Experimental Psychology: General, 121, 15-23. (Original work published in 1935)

Tagliabue, M., Zorzi, M., Umiltà, C., \& Bassignani, F. (2000). The role of long-term-memory and short-term-memory links in the Simon effect. Journal of Experimental Psychology: Human Perception \& Performance, 26, 648-670.

Teichner, W. H., \& Krebs, M. J. (1974). Laws of visual choice reaction time. Psychological Review, 81, 75-98.

Telford, C. W. (1931). Refractory phase of voluntary and associative response. Journal of Experimental Psychology, 14, 1-35.

Umiltà, C., \& Nicoletti, R. (1990). Spatial stimulus-response compatibility. In R. W. Proctor \& T. G. Reeve (Eds.), Stimulus-response compatibility: An integrated perspective (pp. 89-116). Amsterdam: NorthHolland.

Van Selst, M., \& Jolicceur, P. (1997). Decision and response. Cognitive Psychology, 33, 266-307.

Van Selst, M., Ruthruff, E., \& Johnston, J. C. (1999). Can practice eliminate the psychological refractory period effect? Journal of Experimental Psychology: Human Perception \& Performance, 25, 1268 1283.

Virzi, R. A., \& EgEth, H. E. (1985). Toward a translational model of Stroop interference. Memory \& Cognition, 13, 304-319.

WALLACE, R. J. (1971). S-R compatibility and the idea of a response code. Journal of Experimental Psychology, 88, 354-360.

WANG, H. \& Proctor, R. W. (1996). Stimulus-response compatibility as a function of stimulus code and response modality. Journal of Experimental Psychology: Human Perception \& Performance, 22, 1201-1217.
WAY, T. C., \& GoTTSDANKeR, R. (1968). Psychological refractoriness with varying differences between tasks. Journal of Experimental Psychology, 78, 38-45.

WELFORD, A. T. (1952). The "psychological refractory period" and the timing of high speed performance. British Journal of Psychology, 43, $2-19$.

Welford, A. T. (1959). Evidence of a single-channel decision mechanism limiting performance in a serial reaction task. Quarterly Journal of Experimental Psychology, 11, 193-210.

Z Hang, H., \& Konnblum, S. (1998). The effect of stimulus-response mapping and irrelevant stimulus-response and stimulus-stimulus overlap in four-choice Stroop tasks with single-carrier stimuli. Journal of Experimental Psychology: Human Perception \& Performance, 24, 3-19.

\section{NOTES}

1. The terminology action that Hommel (1997) used in his actionconcept model was not restricted to the body-related sensory feedback. Rather, he referred to the action codes as any kind of perceivable action outcome. They could be coded in terms of movement parameters, such as effector, location, distance, or could comprise information about the category and function of the movement in the actor's perception.

2. Pashler, Carrier, and Hoffman (1993) reported that they obtained no PRP effect in their Experiment 1 when T1 required responding to a highor low-pitch tone with the index or middle finger of the right hand and $\mathrm{T} 2$ required making a saccadic eye movement to the location of a visual stimulus. If one assumes that eye movements to stimulus location are not ideomotor compatible, as Pashler et al. did, the relative lack of a PRP effect in Pashler et al.'s study suggests that ideomotor compatibility is not necessary to eliminate the PRP effect. Moreover, similar results were obtained in Pashler et al.'s Experiment 2, in which the S-R relation for the eye-movement task clearly was not ideomotor compatible. In that experiment, red and green stimuli occurred simultaneously in the left and right locations, and the eye movement was to be made to the stimulus of a particular color (e.g., red). Again, the results showed little evidence of a PRP effect. Although the apparent elimination of the PRP effect with saccadic eye-movement responses suggests that tasks with eyemovement responses should be investigated in more detail in the PRP paradigm, it does not provide support for Greenwald and Shulman's (1973) claim that ideomotor compatibility is necessary to eliminate the PRP effect.

(Manuscript received May 16, 2000; revision accepted for publication May 18, 2001.) 